\title{
Towards integrated mapping and assessment of ecosystems and their services in Bulgaria: The Central Balkan case study
}

\author{
Stoyan Nedkov, Bilyana Borisova§, Boian Koulov ${ }^{\ddagger}$, Miglena Zhiyanskil, Svetla Bratanova-Donchevaף, \\ Mariyana Nikolova ${ }^{\ddagger}$, Julia Kroumova ${ }^{\ddagger}$ \\ ‡ National Institute of Geophysics, Geodesy and Geography, Sofia, Bulgaria \\ $\S$ Sofia University, Sofia, Bulgaria \\ | Forest Research Institute - BAS, Sofia, Bulgaria \\ II Institute of Biodiversity and Ecosystem Research - BAS, Sofia, Bulgaria
}

Corresponding author: Stoyan Nedkov (snedkov@abv.bg)

Academic editor: Davide Geneletti

Received: 02 Apr 2018 | Accepted: 31 May 2018 | Published: 11 Jun 2018

Citation: Nedkov S, Borisova B, Koulov B, Zhiyanski M, Bratanova-Doncheva S, Nikolova M, Kroumova J (2018)

Towards integrated mapping and assessment of ecosystems and their services in Bulgaria: The Central Balkan case study. One Ecosystem 3: e25428. https://doi.org/10.3897/oneeco.3.e25428

\section{Abstract}

The aim of the EU Biodiversity Strategy to 2020 isto maintain and enhance ecosystem services (ES) in Europe and requires all Member States to map and assess the state of ecosystems and their services in the respective national territories. The EU-funded project ESMERALDA analyses ES mapping and assessment methods and approaches in their biophysical, social and economical perspectives, as well as their application in different case studies. The project also aims at the development of an integrated and consistent assessment framework. In Bulgaria, methodological guides for evaluation and mapping of the services provided by the nine main types of ecosystems have been prepared together with the respective proposals for their implementation in the national assessment. The Bulgarian research team analyses and tests various aspects of ecosystem services mapping and assessment, such as alternative economic assessments, multi-criteria analyses and biophysical assessment approaches, mapping challenges and local population surveys. In this paper paper, we review the ES activities in Bulgaria and present 
selected mapping and assessment methods tested in the Central Balkan case study area. It provides relevant examples for the implementation of integrated mapping and assessment of ecosystem services at local and regional level, where different mapping approaches and techniques are embedded within diverse policy contexts. The main goal of the study is to investigate how the assessment results can support the integration of the ecological functions of the Central Balkan National Park with the economic opportunities that it creates for the local and regional communities. A tiered approach has been used to organise the mapping and assessment exercises in the study area, in order to meet the needs for integrated ecosystem assessment and overcome the limitations of data availability. At tier 1, the study performs identification and initial ES mapping of the whole area. At tier 2, it applies economic valuation for the Municipality of Karlovo by using statistical data and the contingent valuation method. At tier 3 , the investigation applies modelling methods to assess carbon storage and flood regulation on a larger scale. The results are presented in the form of maps at all levels, which use a uniform 0 to 5 assessment scale. The integrated approach presented here ensures a clear communication of the end results to the respective decision-makers.

\section{Keywords}

Integrated assessment, economic valuation, flood regulation, carbon storage, ecosystem services dysergy, Karlovo Municipality, national park, biosphere reserve

\section{Introduction}

The natural world, its biodiversity and its constituent ecosystems are critically important to human well-being and economic prosperity, but are consistently undervalued in conventional economic analyses and decision-making (UK and NEA 2011). Recently, several global, regional and national initiatives have been set up in order to safeguard biodiversity and the services that ecosystems provide through ecosystem assessments (Schröter et al. 2016). The EU Biodiversity Strategy to 2020 aims, under its Target 2, to maintain and enhance ecosystem services (ES) in Europe. Action 5 of the strategy requires all Member States to map and assess the state of ecosystems and their services in their national territories. The working group on Mapping and Assessment of Ecosystems and their Services (MAES) has been established to coordinate and oversee the activities under action 5. It has developed a methodological framework to ensure the consistency of the implemented approaches (Maes et al. 2013). The EU-funded project, ESMERALDA (Enhancing ecosystem sERvices mApping for policy and Decision mAking), aims to deliver "flexible methodology that can simultaneously provide innovative building blocks for panEuropean, national and regional ES mapping and assessment" (ESMERALDA 2015). It analyses ES mapping and assessment methods and approaches in their biophysical, social and economical perspectives, as well as their application through testing in different case studies (Burkhard 2018). The tiered approach is promoted as an instrument to structure a variety of methods by applying them to different complexity levels (Grêt- 
Regamey et al. 2015, Sieber et al. 2017). Furthermore, the work continues towards the development of an integrated and consistent assessment framework, in which different mapping approaches and techniques are embedded within diverse policy contexts.

Bulgaria has been carrying out a wide range of research which analyses various aspects of the Natural Capital concept and its derivative - Ecosystem Services. Investigations include pilot alternative economic assessments (Rashev 2003, Zevurdakis et al. 2007) and various mapping and assessment studies (Assenov et al. 2016, Borisova et al. 2015, Boyanova et al. 2014, Nedkov and Burkhard 2012) that result in a rich collection of scientific ideas and practical knowhow related to ecosystem services governance (for more details see the next section). The institutionally coordinated process in the country for the implementation of the ES assessment and mapping commitments started in 2014 with preliminary mapping, as an integral part of the National Priority Framework for Natura 2000 Activities. In 2017, with the support of the Ministry of Environment and Waters (MoEW), methodological guides for evaluation and mapping of the services provided by the nine main types of ecosystems, identified in the Bulgarian geographic space, have been prepared together with the respective proposals for their implementation in the national assessment. The mapping and assessment of all ecosystem types in Bulgaria were finalised in 2017 with seven projects for assessment and mapping. These activities have led to significant progress in the country - according to the MAES barometer from level 10 in 2015 to level 20 ( $\max 26$ ) in 2017. At the moment, the EU and Bulgaria, in particular, face the following general phases: concrete, coordinated, methodologically consistent socio-economic evaluation of the ES and introduction of the values obtained in the national statistical systems and the planning and governance systems at all geospatial levels (Koulov and Borisova 2018).

The Central Balkan National Park, together with municipalities at its boundaries, have been test sites for ES mapping and assessment activities carried out under the framework of several research projects at the national, regional and local scale (Assenov and Borisova 2016, Borisova et al. 2015, Dimitrova et al. 2015, Nedkov et al. 2017, Zhiyanski et al. 2016). The Municipality of Karlovo has also been involved as one of the urban city labs in the Joint Research Center (JRC) urban pilot EnRoute project. (Maes et al. 2017). The establishment, under the Seville Strategy, of the Central Balkan Biosphere Reserve in 2017, has also included the surrounding municipalities in its development zone and, thus, further contributes to the much closer involvement of the local administration in the planning and sustainable management of their natural capital. The area of Central Balkan National Park, together with the surrounding municipalities, has been used in a number of case studies for testing the ideas, concepts and methods within the ESMERALDA (2014-2018) (Geneletti et al. 2018) and "The Mountain - Models of Socio-economic and Cultural Development: Regional Challenges and Transborder Cooperation (2011-2018)" projects. These studies review, evaluate and consolidate the existing datasets for the area, including the network of protected areas in the Central Balkan. They apply a holistic approach which ensures comprehensive identification of the main drivers of land use change. The studies also analyse the likely impacts of these drivers on the supply of ecosystem services from the selected ecosystems and present mapping and assessment options for further sustainable development. 
In view of the above, the main objectives of this paper are:

- to make a review of the ES mapping and assessment activities in Bulgaria in relation to the MAES process and select appropriate methods and approaches for the ES mapping and assessment within the boundaries of the case study area;

- $\quad$ to present the selected mapping and assessment methods used at the different scales and tiers;

- to discuss the applicability of the selected methods in the context of integrated ecosystem assessment.

\section{Mapping and assessment of ecosystem services in Bulgaria}

\section{Review of ES mapping and assessment studies in Bulgaria}

We collected all available mapping and assessment studies published in scientific journals, grey literature and project reports. They were analysed according to several criteria including geographical scope, ecosystems services which were mapped and assessed, applied methods, scale, tier and purpose of the study (see Suppl. material 1).

The studies cover various topics including multi-criteria analyses and biophysical assessment approaches (Bratanova-Doncheva et al. 2014, Nedkov et al. 2014), mapping challenges (Nedkov et al. 2014, Nedkov and Burkhard 2012, Nedkov et al. 2016, Nedkov et al. 2017, Boyanova et al. 2016, Boyanova 2015, Markov and Nedkov 2016), studies focusing on different geographic scales (Boyanova et al. 2014, Pehlivanov et al. 2014, Zhiyanski et al. 2016, Dimitrov et al. 2018) and diverse geospatial areas (Assenov et al. 2016, Avetisyan et al. 2016, Borisova et al. 2015, Nedkov 2011) and local population surveys (Assenov and Borisova 2016, Borisova et al. 2015) that result in a rich collection of scientific ideas and practical know-how related to ecosystem services governance (Dimitrova et al. 2015, Koulov et al. 2017, Nedkov et al. 2017).

Several targeted areas test the practical application of a GIS-based mapping, assessment and valuation of ecosystem services model in real world administrative territorial units at the local level in Bulgaria (Ivanova et al. 2016, Koulov et al. 2017,Boyanova et al. 2014, Boyanova et al. 2016, Nedkov and Burkhard 2012, Nedkov et al. 2016, Nedkov et al. 2014). The idea has been to identify, test and, to the greatest possible extent, overcome the challenges in the application of the model at the smallest and, hopefully, simplest, possible scale of practical importance to geospatial statistics, accounting and governance and improve its analytical and valuation potential. One helpful result has been the introduction of the term "ecosystem services dysergy" in the valuation's theoretical framework. Koulov et al. 2017 consider ES dysergy, as opposed to the widely used term "ES synergy", to be the negative effect, which is produced by the interdependencies and interactions amongst ecosystems; it subtracts from the total value added for the produced services. The geospatial identification, analysis and visualisation of hotspots, synergy and dysergy areas 
should exhibit much more informative results in the many and diverse cases of simultaneous utilisation of ES.

The same study emphasises the importance of active and continuous two-way communication with public leaders in all spheres and government levels, a "critical mass" of the socially active population plus an ever open group of stakeholders. These groups should be necessarily and sufficiently convinced that the utilisation ESS concept will not just suit the local geographic conditions, but also provide the locality with certain comparative advantages with clearly identifiable benefits for the wellbeing of the majority or important section of the population, e.g. young people. Such advantages are expected to represent a significant step towards balanced and sustainable governance of the respective administrative unit. In the same context, Koulov and Borisova (2018) offer a critical view of the current experience with the Ecosystem Services' concept in Bulgaria with the accent on the terminology and geographic scales, as well as the opportunities and limitations it presents to the practice of sustainable governance at this time. Tomova and Borisova 2018 use the example of the newly established post-Seville "Central Balkan" Biosphere Reserve in Bulgaria to discuss the opportunities for its use as a tool for long-term landscape planning and, thus, facilitate the understanding of the full potential for ecosystem services by turning the reserve into a practical learning lab for sustainable development. Pilot studies by Assenov and Borisova (2016) demonstrate that, despite the significant lack of information on the concept of ecosystem services and related basic terminology, the understanding of the need for a new approach to management of the natural resources is present.

The literature review shows that several studies use the benefits of natural units/ geosystems, as a carrier of information on ecosystem services assessment (Avetisyan et al. 2016, Borisova et al. 2015, Nedkov et al. 2017, Nedkov et al. 2016). By way of underlining the link "structure - functions - services", Borisova et al. (2015) conceptualise ecosystem services as a complex result of the landscape structural heterogeneity and ecological status (through the Hemeroby Index).

\section{Methodological framework for mapping and assessment of ecosystems and their services in Bulgaria}

Ecosystems are mapped by building up a series of overlays of significant factors, such as the distribution of different communities of organisms, the biophysical environment (soil types, drainage basins, depth of water bodies) and spatial interactions (e.g. migration patterns). Ecosystem boundaries are likely to coincide with discontinuities in these factors. Thus, ecosystems within each category share a suite of climatic, geophysical and biochemical conditions, biological conditions (including species composition and interactions) and socio-economic factors shaping land cover (e.g. dominant uses by humans, which tend to differ across ecosystems).

In Bulgaria, the ecosystems mapping and assessment process has been performed following the National Methodological Framework. The methodologies are in line with the 
analytical framework proposed by the European Commission (Maes et al. 2013). In 2015, in the frame of the Programme BG03 Biodiversity and Ecosystems, funded by the financial mechanism of the EEA, the methodology and 7 mapping projects have been prepared and carried out at national level. The National Methodological Framework, produced within the scope of the Methodological Support for Ecosystem Services Mapping and Biophysical Valuation (MetEcoSMap) Project (2015-2017), provides a national typology of ecosystems that combines the CORINE Land Cover (CLC) classes with the European Nature Information System (EUNIS) habitat classification types. In addition, water ecosystem indicators (freshwater and marine) are also structured to be as close as possible to indicators for the Water Framework Directive and Marine Strategy Framework Directive. In this manner, compatibility is ensured between the EU-level classifications used in different types of legislation (Chipev et al. 2017, Bratanova-Doncheva et al. 2017). The Methodological Framework includes the methodology for mapping and assessment of the condition of each of the nine ecosystem types and the ecosystem services that they provide, a monitoring guide at the ecosystem level and an in situ verification guide. The implementation of the methodology was carried out through seven projects for assessment and mapping of: freshwater ecosystems (FEMA), wetlands (WEMA), grassland ecosystems (IBER-GRASS), sparsely vegetated land ecosystems (SPA-Ecoservices), heathland and shrubs ecosystems (HSE), cropland ecosystems, urban areas (TUNESinURB) and forest ecosystems (For our Future).

The general scheme of the assessment and mapping process is presented in Fig. 1 (Bratanova-Doncheva et al. 2017). The scheme and steps proposed by MAES have been followed. The National Methodological Framework needs to be extended and modified, in order to follow the next steps, as the ecosystem research evolves and relevant EU legislation and guidance documents are adopted. The step-by-step process of the framework is presented in the following paragraphs.

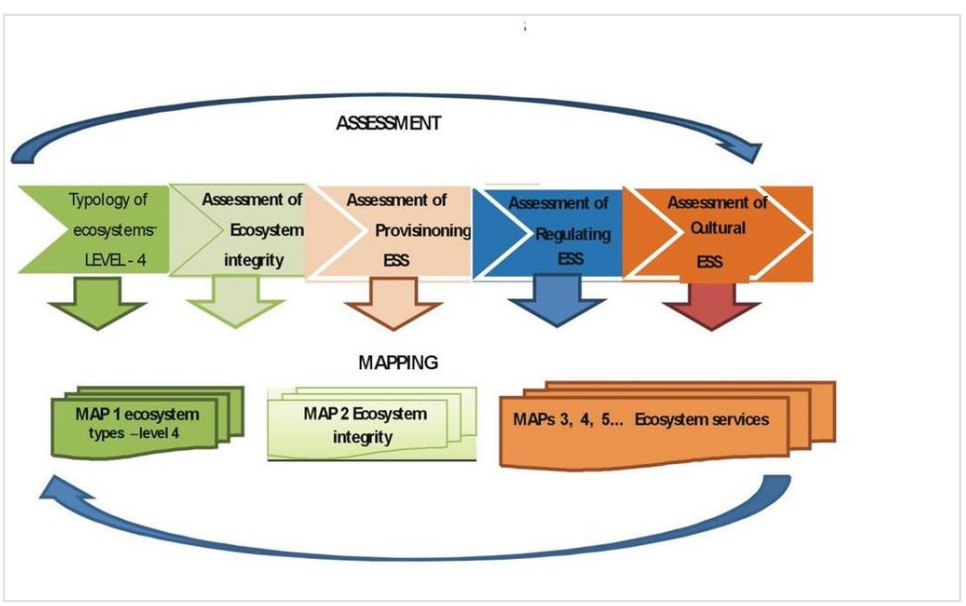

Figure 1.

General scheme of the assessment and mapping process (Bratanova-Doncheva et al. 2017). 


\section{The first phase is to identify and map the existing ecosystem types in the given area.}

The 5 steps of elaborating the ecosystem typology in Bulgaria include:

Step 1 - Identification of the ecosystem type - levels 1 and 2 MAES

Step 2 - Identification of the ecosystem levels 3 and 4 of the given type

Step 3 - Collection of data (national data sets)

Step 4 - Identification of the gaps in data and areas with data uncertainty

Step 5 - Mapping (Production of maps of ecosystem types) and monitoring of trends.

\section{The Second phase involves assessment and mapping the ecosystem integrity and condition.}

The overarching concept of the ecosystem condition assessment in Bulgaria is the concept of ecosystem integrity, described in Burkhard et al. 2012. The key indicators for assessing the condition within the ecosystem integrity concept should allow the identification of key elements of ecosystem integrity (such as, abiotic heterogeneity, biodiversity, mass budget, water budget, energy budget), the sensitivity to environmental changes, as well as the critical relevance for environmental modelling. Naturally, the indicators vary from ecosystem type to ecosystem type.

In order to assess the condition of the ecosystems in Bulgaria, scores are assigned (from 1 to 5) depending on the measured/assessed values of every indicator (by expert evaluation made during the preparation of Part B methodologies and applied during the mapping for each specific polygon), thus reflecting the "condition" of the process or the structural element of the ecosystem for which the indicator is relevant. The scores correspond to the scale from 1 (bad condition) to 5 (very good condition). In order to collate all separate indicator scores into one single measure of ecosystem structural-functional condition, we introduced an Index of Performance (IP) for a particular ecosystem. The IP is calculated as the ratio of the sum of the indicator scores to the maximum possible indicator sum.

\section{The third phase includes assessment, mapping and monitoring of ecosystem services}

The current methodology and other relevant parts of the National Methodological Framework contribute to the practical implementation of the ecosystem approach in the assessment of ecosystem services on a national scale, as follows:

Step 1: List, using the CICES classification (Haines-Young and Potchin 2013), the ecosystem services supplied by a given ecosystem type. Prioritisation is made by expert assessment, based on the importance of the single indicators/parameters and data availability at the chosen scale. 
Step 2: List the components of the ecosystem or ecosystem mosaics that supply each service or service bundle, relevant to the respective landscape and purpose. Ecosystem components can include particular species, habitats, communities or functional groups (such as 'large trees' or 'pollinators').

Step 3: Identify those components that make the greatest contribution to the service supply (i.e. the critical ecosystem components). For some services, there may be critical ecosystem components that are common across a range of ecosystem types.

Step 4: Establish the relationship between the condition (state) of the critical ecosystem components and the supply of the service, which is important in selecting the indicators used to assess the condition on the basis of data from statistics, environmental monitoring or reporting under EU environmental legislation. The establishment of the ecosystem condition-service supply relationship is more important when there are several critical ecosystem components involved in the supply of a given service, as aggregating their condition into one 'service supply' is not necessarily a case of simply adding them together.

Step 5 is divided into two parts:

Step $5 a$ involves the assessment of the baseline condition of the critical ecosystem components (i.e. ecosystem service supply) using the indicators from relevant EU environmental directives. The 'status' assessments of these indicators are used to evaluate the ability of the critical ecosystem components to supply the ecosystem service of interest, in terms of whether the indicators 'pass' or 'fail' in meeting the objectives of the relevant directive (e.g. favourable conservation status). This would mean that the critical ecosystem component is in 'good' or 'bad' condition, respectively and reflects its ability to supply the service of interest.

Step $5 b$ uses information on the pressures acting on the ecosystems, the trends in those pressures and the link between pressures and condition to establish the potential impacts on the supply of the ecosystem service over time, at least qualitatively.

Step 6: Combining the above two steps (Steps 5a and b) and aggregating all the critical ecosystem components along the state-service relationship (from step 4) would result in an assessment of the ability of the ecosystem to supply the service, also considering the DPSIR (Drivers, Pressures, State, Impact, Response) framework.

The final step includes the assignment of scores (by expert assessment) indicating the capacity of the given ecosystem to deliver a particular service - scores from 1 (very low capacity) to 5 (very high capacity) (Burkhard et al. 2012). Scores are assigned to the baseline and where possible, also to the monitoring measurements. A zero score means that the service is not relevant for this ecosystem (for more information see the National Methodological Framework for mapping and assessment of ecosystems and their services in Programme BG03 "Biodiversity and ecosystems") 


\section{Integrated ES assessment in the Central Balkan: Approaches and methods}

Mapping and assessment of ES, as defined in the Biodiversity strategy to 2020 , is a comprehensive process that builds on various individual tasks and their systematic integration. Therefore, an integrated and operational framework is needed to support and coordinate these activities (Burkhard et al. 2014,Burkhard et al. 2018). The core of the integrated assessment is the common framework, proposed by MAES, which includes mapping of ecosystems, assessment of ecosystems condition and the services they provide (Maes et al. 2013). This framework is further developed by Burkhard et al. 2018 and provides step by step guidelines and incorporates the policy and decision-making context. Our study follows the framework above and the structure of this section is organised into three subsections corresponding to the framework. The first part deals with the identification of research and policy questions that should be addressed (step 1). The second is related to the process of ecosystems identification, mapping of ecosystem condition and ecosystem services (steps 2 to 7). The third is about integration, dissemination and communication of the outcomes (steps 8 and 9).

\section{Research and policy issues}

\section{Case study area}

The case study area is located in Central Bulgaria and covers the central part of the Balkan Mountains (Stara Planina in Bulgarian) and the surrounding areas (Fig. 2). The spatial coverage is outlined by following both natural and administrative criteria including all the municipalities that have parts of their areas included in the Central Balkan National Park. In total, the area covers 299894 ha $\left(2998.9 \mathrm{~km}^{2}\right)$ where 73536.5 ha or $24 \%$ of the case study area is designated as protected (37 areas in total). The most important protected area is the Central Balkan National Park (71825.5 ha) which encompasses nine other protected areas within its borders. The average altitude is $913 \mathrm{~m}$ ranging from $265 \mathrm{~m}$ in the Karlovo Plain to $2376 \mathrm{~m}$ at the Botev Peak (the highest summit in the Balkan Mountains). Although the study area is relatively small, its nature is quite diverse, due to the influence of the Balkan Mountain Range. This leads to the formation of different hydro-climatic conditions in the higher altitudes and in the northern and southern parts of the mountain. There are three types of climate: temperate continental in the north, transitional to Mediterranean in the south and mountainous in the central part and in the areas above $1000 \mathrm{~m}$. The average annual temperatures vary from south to north from $11.1^{\circ} \mathrm{C}$ (in the Town of Karlovo) to $10.0^{\circ}$ $\mathrm{C}$ in the Town of Troyan and decrease to $0.7^{\circ} \mathrm{C}$ at Botev Peak. The south part of the area is drier than the north part. The mean annual precipitation changes from 550 to $800 \mathrm{~mm}$ and the quantities rise to $1100 \mathrm{~mm}$ with the increase in altitude. The vegetation is characterised by typical altitudinal zoning. In the lower parts, the vegetation is presented by Oak and Oak-Hornbeam forests, followed by beech forests in the areas above $800 \mathrm{~m}$ and mountain grasslands at the highest parts of the mountain. 


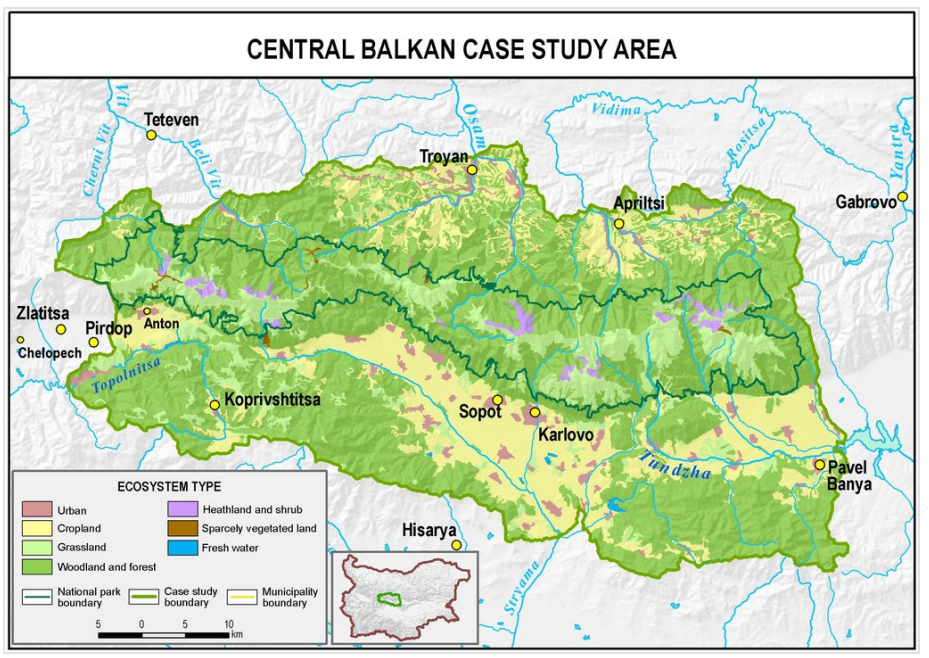

Figure 2.

Central Balkan case study area.

The study area covers partially the territory of the following nine municipalities - Teteven, Anton, Pirdop, Karlovo, Sopot, Sevlievo, Apriltsi, Troyan and Pavel Banya. Only two of them - Karlovo (103911 ha) and Sopot (5630 ha) are situated entirely within the case study area. There are 82 settlements with a total population of 128626 residents while $58 \%$ of the population (74205 inhabitants) lives in urban areas. The most populated towns are Karlovo (25715 inhabitants) and Troyan (23623 inhabitants). The population of Karlovo Municipality is estimated at 50650 residents with a decreasing trend, due to the negative growth rate.

The Central Balkan National Park occupies the higher parts of the mountain and varies in altitude from $550 \mathrm{~m}$ to $2376 \mathrm{~m}$. The park is part of the PAN Parks network and is one of the largest and the most valuable protected areas in Europe, ranked at category 2 by IUCN. It performs the functions of a significant ecological corridor in Eastern Europe, as well as a nexus for genetic exchange between the southern Balkans and the Asia Minor Peninsula. The Central Balkan National Park belongs to the Rhodope montane mixed forests terrestrial ecoregion of the Palearctic temperate broadleaf and mixed forest and is home of rare and endangered wildlife species and communities. The flora is represented by 2340 species and subspecies of plants. Forests occupy $56 \%$ of the total area. There are 59 species of mammals, 224 species of birds, 14 species of reptiles, 8 species of amphibian and 6 species of fish, as well as 2387 species of invertebrates. The National Park includes nine nature reserves that cover $28 \%$ of its territory. Since 2017 , the Central Balkan National Park has formed the core and the buffer zone of the new Central Balkan Biosphere Reserve (Fig. 3). Different parts of the case study area were used as smaller scale case studies in order to demonstrate the application of the multi-tiered approach at different levels of scale. Municipality level (Karlovo municipality) was used to present the application of economic valuation at tier 2, watershed level (Vidima watershed) and town level (Karlovo) were used to present the application of biophysical methods at tier 3. 


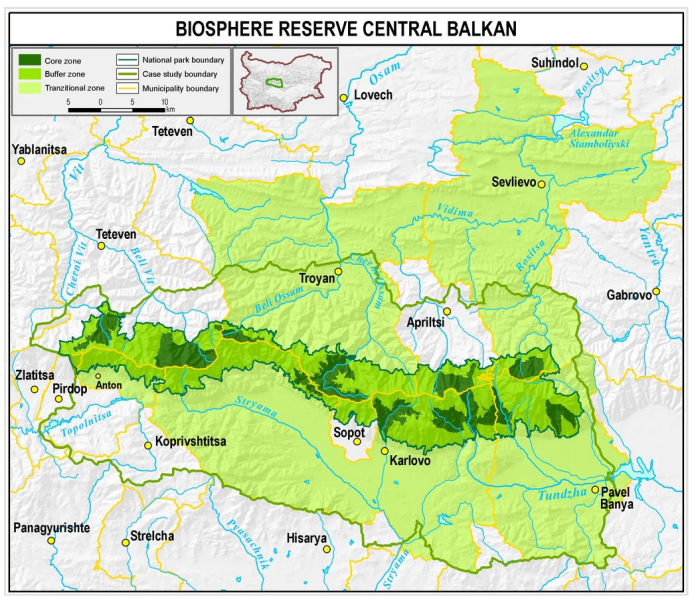

Figure 3.

Central Balkan biosphere reserve (source: project "Linking nature protection and sustainable rural development").

The studies in the area of Central Balkan include flood hazard assessment and mapping of flood regulation in the upper part of the Yantra basin, natural capital assessment and application of the contingent valuation method in the Apriltsi and Kalofer municipalities (Borisova et al. 2015, Assenov and Borisova 2016), ES valuation of the forests in Central Balkan National Park (Dimitrova et al. 2015), mapping of carbon storage capacity in the Beklemeto area (Zhiyanski et al. 2016) and urban ecosystem assessment in the Karlovo Municipality - a pilot study in the national MAES-related activity (Nedkov et al. 2017). Most of these investigations have been conducted with the active support of the municipal and National Park administrations, which strengthens the policy context of the conducted research. The Central Balkan study area encompasses a part of a mountain region which suffers from a range of natural and socio-economic disadvantages (e.g. demographic loss, remote and limited access areas, higher climate change vulnerability), but it also provides key resources and ES to people and societies (water, renewable energy, protection against natural hazards, opportunities for tourism, natural and cultural diversity etc.). Central Balkan and the protected areas in it are 'hotspots of biodiversity', containing many ecosystems with rather low anthropogenic influence, particularly at higher altitudes, often in protected areas. Mountain ecosystems are particularly fragile and subject to both natural and human drivers of change, which implies the need forbetter knowledge of their specificities to produce sufficient conservation measures.

\section{Policy context}

The application of the Ecosystem Services (ES) concept to the Central Balkan case study facilitate the adoption and/or further establishment of a number of policy instruments for a science-based, sustainable territorial governance, amongst which: the need for regular monitoring, immediate, free and open access to data, information and know-how; 
integration of scientific knowledge in civic affairs governance practice; continuous planning process with in-built policy alternatives coupled with respective impact assessments; continuous education, proper motivation and constant involvement of the stakeholders and the public (Burkhard et al. 2010,Primmer and Furman 2012, Rosenthal et al. 2014, Koulov et al. 2017, Guerry et al. 2015). The research activities related to sustainable development and mapping and assessment of ES have proven able to smooth out some of the tensions that often arise between the protection and conservation functions of the protected areas in mountain regions and the municipal administrations, which are usually more focused on securing local economic opportunities and short-term improvement of social wellbeing. In the days when the Central Balkan National Park (NP) was in its infancy, municipalities often used to hold it responsible for missed economic opportunities, which ultimately resulted in their opposition to certain Park-related projects. At this time, after experiencing some of the positive impacts of nature protection policies, municipalities have gradually started to cooperate.

The overall territorial impact of the Central Balkan NP, category II in the IUCN classification, on the development of its region, however, still presents significant challenges to comprehensive assessment, due to a number of factors, amongst which the sheer number and the diverse and multi-scale character of the institutions and actors involved. The Park itself is managed by the 1998 Protected Territories Act (Suppl. 1, Art. 8.1, Amen. SG 28/2000, Amen. SG 77/2002) and administered by the Ministry of Environment and Waters and its National Nature Protection Service. The Service is responsible for development of protection and conservation strategies, programmes, plans and other regulatory documents. Thus, the direct impacts on the Park are strongly related to the implementation of the national conservation policy.

Simultaneously, Central Balkan is the second largest national park in Bulgaria and its territory is included in four NUTS 2 economic planning regions, five NUTS 3 administrative regions (oblast) and nine LAU 1 self-governing administrative regions (obshtina) with thirty settlements, including seven towns. Their strategic and short term planning and policy documentation does not always coincide in time period, territorial scope, quality or level of implementation. For example, most municipal development plans (Troyan, Karlovo, Sevlievo, Pavel Banya, Anton) provide a strategic framework and programme for their development for the 2014-2020 programming period, while the Pavel Banya Municipal Plan still refers to the previous 2007-2013 planning period. The comparative analysis of the basic local development planning instruments - the municipal development plans - shows generally weak intra-regional and inter-sectoral connection and even less cooperation. Overall, some of the plans' objectives are nature conservation-orientated and focus on the preservation of natural resources and natural heritage. They espouse implementation of international conventions and national conservation guidelines, e.g. Natura 2000, CBD, UNESCO MaB Programme and Seville Strategy, National Priority Framework for Action in Natura 2000 Areas. However, the EU level, national and regional development documents all focus on the population settlements and, particularly, the urban centres and do not directly connect their wellbeing to the Central Balkan NP, which is the legal responsibility of other ministries and agencies. 
The local economic policy context in the Central Balkan NP region almost uniformly promotes development of sustainable tourism and ecotourism, nature and cultural tourism IN particular, are viewed as the key potential. This and most other envisioned economic activities (e.g. measures to support the shift to organic farming, local livestock breeding and silvi-culture bio-products, sustainable energy production) indicate a strong thematic link to the eco-potential of the National Park. Municipal plans provide ample evidence that, at the expert level at least, an increasing understanding has been shaping for the need for valorisation of a number of concrete ecosystem services, including in the forestry and water sectors and natural hazards control (i.e. forest fires, soil erosion, avalanches, floods and climate regulation. The main challenge in terms of regional territorial strategies and policies is to successfully combine the protection of natural assets and landscapes with valuation of ecosystem services and sustainable development.

This review of the ES studies in the Central Balkan area gains further significance in light of the latest developments in its ecological status. As a result of the implementation of the Seville Strategy for Biosphere Reserves (UNESCO 1996), which targets the "harmonious coexistence" between Man and Nature through integration of good policies and practices in biodiversity conservation and sustainable development of local communities, at its June 2017 meeting in Paris, UNESCO's Council of the Man and the Biosphere Programme endorsed the creation of a Central Balkan Biosphere Reserve. In fact, this distinction provides further stimuli for economic and socio-cultural development not only of the local municipalities, but of the region as a whole.

The geographic structure of the new Biosphere Reserve consists of three functional zones:

1. a core area, which comprises the nine reserves of the existing Central Balkan National Park;

2. a buffer zone, which includes the rest of the National Park's territory; and

3. a specially created "development zone", which encompasses $80 \%$ of the area of the "Central Balkan Biosphere Reserve" and acts as a transition area between the National Park as a whole and the ecologically unregulated parts of the local municipalities (Fig. 3).

The Biosphere Reserve's development zone is made up of territories from the following municipalities: Karlovo, Troyan, Sevlievo, Pavel Banya and Anton. It is an area of geospatial integration of the ecological (conservation and protection) functions of the National Park with the economic opportunities that the Park creates for the population in the region, including particular types of tourism and recreation services and a number of forest- and mountain-related ES.

According to the Lima Action Plan (2016-2025), a key role for the efficiency of biosphere reserves is their recognition as a source of ecosystem services and the provision of a longterm vision for the protection of these services (LAP 2016). On this basis, this work 
endorses the opinion of Tomova and Borisova 2018 that identification, evaluation and mapping of ES contribute for:

1. Enlargement of the environmental information base and its decision-making support functions, which go beyond the Natural Resources concept;

2. Deepening the role of the financial mechanisms in environmental policy and natural resources management;

3. Raising the value of spatial and sectoral planning analyses and increasing their sensitivity to landscape versatility.

Comprehensive identification and consideration of the dependence of the local population on the ES in the nearby areas makes valuation of the ES an important factor in sustainable landscape planning and territorial integration policy-making (Borisova 2013). As GrêtRegamey et al. 2008 point out, appropriate selection and valuation of ES in a spatially explicit form facilitates the identification of the most beneficial locations for new development.

The studies above target the area of the following Natura 2000 zones: "Central Balkan" BG0000494, "Central Balkan buffer" BG0001493 and BG0002128 and the municipalities of Karlovo and Troyan. A series of activities, related to schemes for payments for ES (restoration and maintenance of a locally characteristic gene pool in protected areas - rare local animal breeds), support for organic livestock breeding (in ecosystems of high conservation value), as well as co-financing of economic activities, where the revenues are used to protect biodiversity, have been formally approved within the scope of the territory under investigation. These activities are part of the successful project of six Bulgarian NGOs, four Swiss organisations and the Ministry of Agriculture, Foods and Forests through the Executive Agency for Selection and Reproduction in Animal Breeding, named "For the Balkans and the Humans" (2012-2016), that won an European Commission "NATURA 2000" award in the "Socio-Economic Benefits" category (BBF 2016).

\section{Data availability and application of a tiered approach}

Mapping of ecosystems and their services depends to a very large extent on the availability of spatial data. The requirements to the data quantity and quality are strongly influenced by the scale of mapping. Larger scale mapping requires more detailed spatial data with higher accuracy. Some sources of data for the Central Balkan meet these requirements but none of them covers the whole study area. The data generated by the projects, which implemented the methodology for mapping and assessment, are organised in spatial datasets representing the ecosystems at the third level of the MAES typology. They correspond to scale 1:25000 and have aminimum mapping unit of 0.25 ha. There are actually nine different datasets, one for each main ecosystem type, which are not fully compatible. Furthermore, they do not cover the NATURA 2000 zones, which cover a significant part of the study area. More detailed datasets exist at municipality, city and watershed level which have been used for mapping and assessment of the selected ecosystem services. For instance, the results of the hydrologic modelling of the Vidima Watershed (Boyanova et al. 2016) has been used for assessment of the flood regulation 
ecosystem service and the carbon storage data for the urban ecosystems in Town of Karlovo (Nedkov et al. 2017) has been used for assessment of the global climate regulation.

The CORINE land cover dataset is the only one available that covers the whole study area. While it is too coarse for municipality or city level mapping and assessment, it is sufficient for a general overview of the ecosystems in the area and identification of relevant ecosystem services. The tiered approach has been used to organise the mapping exercises in the study area, in order to meet the needs for integrated ecosystem assessment and overcome the limitations of data availability. At tier 1, the studies perform identification and initial ES mapping for the whole case study area using CORINE land cover data for ecosystems delineation and expert-based assessment of the ecosystem services. At tier 2, it applies economic valuation for the Municipality of Karlovo by using statistical data and the contingent valuation method. At tier 3 , the investigation applies more complex modelling methods to assess two different ecosystem services on a larger scale. Quantification of carbon storage for the assessment of global climate regulation is applied in the Karlovo Town and assessment of flood regulation based on GIS-based hydrological modelling is applied in the Vidima Watershed.

The tiered approach applied at different scales in frames of one and the same territorial unit illustrate very well the spatial integration of the assessed ecosystem services at different scales using different methods (Table 1).

Table 1.

Overview of mapping and assessment methods applied in the case study area at different tiers and scales.

\begin{tabular}{|l|l|l|l|l|l|}
\hline Case study & Scale & Tier & $\begin{array}{l}\text { Ecosystem } \\
\text { services }\end{array}$ & $\begin{array}{l}\text { Type of } \\
\text { method }\end{array}$ & Method \\
\hline Central Balkan & $\begin{array}{l}\text { Whole case } \\
\text { study }\end{array}$ & 1 & $\begin{array}{l}\text { Bundle of } \\
\text { relevant services }\end{array}$ & $\begin{array}{l}\text { Biophysical/ } \\
\text { Social }\end{array}$ & Spreadsheet \\
\hline $\begin{array}{l}\text { Karlovo } \\
\text { Municipality }\end{array}$ & $\begin{array}{l}\text { Municipality } \\
\text { level }\end{array}$ & 2 & $\begin{array}{l}\text { Bundle of } \\
\text { relevant services }\end{array}$ & Economical & $\begin{array}{l}\text { Market price, Value transfer, } \\
\text { Replacement cost, Net financial } \\
\text { contribution (NFCu) }\end{array}$ \\
\hline Karlovo town & Town level & 3 & $\begin{array}{l}\text { Global climate } \\
\text { regulation }\end{array}$ & Biophysical & Spatial proxy model \\
\hline $\begin{array}{l}\text { Vidima } \\
\text { Watershed }\end{array}$ & $\begin{array}{l}\text { Watershed } \\
\text { level }\end{array}$ & 3 & Flood regulation & Biophysical & Process based modeling \\
\hline
\end{tabular}

\section{Mapping and assessment}

\section{Identification and initial ES mapping}

The first step in the mapping and assessment procedure is to identify the ecosystem types and the relevant ecosystem services in the case study area. For this purpose, the studies 
use the spreadsheet method for ecosystem services assessment which is based on land cover/ES matrix approach (Burkhard et al. 2014, Burkhard et al. 2009, Burkhard et al. 2012). The matrix links ecosystem services to CORINE land cover classes and, at the intersections, the ES capacities are assessed on a 0 to 5 relative scale. There are 20 land cover classes in the Central Balkan case study area which are arranged on the y-axis of the matrix (see Figure 5 in the next section). The relevant ecosystem services for the case study area were selected using the CICES classification by the authors of this study and they were placed at the $\mathrm{x}$-axis of the matrix. The scores for combination of land cover class and ES were made by team of experts during a fieldwork campaign in the study area. The team consisted of 14 researchers and $\mathrm{PhD}$ students from different fields including forestry, ecology, hydrology, climatology, landscape ecology, economical geography, regional planning, tourism and civil engineering. They were involved in a $\mathrm{PhD}$ seminar in the Central Balkan case study area in July 2016, organised under the project "The Mountain - Models of Socio-economic and Cultural Development: Regional Challenges and Transborder Cooperation" of the Center of Excellence in the Humanities - Sofia University "St. Kliment Ohridski". After the fieldwork, they filled the matrix and their scores were collected in separate spreadsheets. The scores for each land cover/ES combination were calculated as an average of the all 14 spreadsheets.

\section{Economic valuation at municipality level}

Availability of data for the purposes of ES valuation at the municipal level is a problem significantly more serious than at the higher levels. National level statistics and Eurostat are better equipped with data for provisioning ES assessment; however, thematic limitations and information deficits do exist. Eurostat's coverage of the local (LAU) scale is generally quite scant, so the demand is currently satisfied by data transfer methods which utilise the regional and national scales (NSI 2015a, NSI 2015b, NSI 2016, MAF 2014). At times, even global statistics are utilised through a procedure which greatly lowers the degree of valuation relevance and hampers its validation (Koulov et al. 2017).

ES research in Bulgaria can partially rely on local business activity data, such as tangible fixed assets, number of active enterprises and short-term business initiatives, as well as inputs and outputs data. In some instances, data are obtained from the internal statistics of individual business entities, state institutions and associations or previously conducted research projects (as is the case with the Central Balkan National Park Directorate and the investigation of Dimitrova et al. 2015 under the OP "Environment 2007-2013").

The contingent valuation method, using a survey of 12 questions, has also been used in the Apriltsi Municipality and the Kalofer Mayorality. It is primarily orientated towards determining the local population's knowledge, preferences and dependences regarding ecosystem services.

Database optimisation involves results obtained by assessment of the ecological status and, respectively, the potential of ecosystems to provide services. It is based on analysis of information from: the assessment of the state of the habitat types represented in NATURA 2000 protected sites within the CLC Classes at the respective municipality (with respect to 
the criteria: biodiversity, typology, natural character, rarity, size, vulnerability and stability/ instability), validated by field observation data.

To summarise, the employed system of valuation methods, some of which are used indirectly, includes: Contingent Valuation, Market Price, Value Transfer, Replacement Cost and Net Financial Contribution (NFCu). The selection of concrete methods depends mostly on the possibility and practicality of transferring data or using generalisation methods, as well as the spatial variations of ES under evaluation. The total economic value (TEV, €/ha/ $\mathrm{yr}$ ) of the selected services, which form the current and future basis of the local economy and the welfare of the population, on the territory of the Karlovo Municipality (Koulov et al. 2017 ) is calculated as a sum (Formula 1 - Fig. 4)

$$
T E V=\sum_{i=1}^{n} \sum_{j=1}^{m} E S V_{j}
$$

Figure 4.

Formula 1.

where: TEV is total economic value of ecosystem services; $n=11$ is the number of the raster layers; ESVj is the economic value of ES class type j; and $m$ is the number of ecosystem services class types in layer i. The fact that the actual provision of one ES is dynamically linked to the provision of other services has been accounted for in the analytical process, which accompanies the valuation. Additionally, the study above ventures to analyse the impact of existing dysergies on the ES flows and attempts to incorporate their financial value. Thus, an intermediate step has been included, where necessary, in the course of the valuation, which assesses the complex and dynamic character of ecosystem interactions and their mutual interdependencies.

For mapping purposes, the investigations interpret the CORINE Land Cover 2012 classes (NRC 2014) as geospatial units for identification of ecosystem types, classes and subclasses (Maes et al. 2013) and next - for valuation of the ES classes and class types (CICES v4.3).

\section{Biophysical mapping at watershed and town level}

\section{Flood regulation mapping and assessment}

Flood regulation has been assessed in the Vidima Watershed which is located in the northern part of the Central Balkan case study area. Vidima River is the left tributary of Rositsa River which is the main tributary of Yantra River (see Fig. 1). The Vidima Watershed, upstream of the Town of Apriltsi covers an area of 7677.9 ha with an elevation ranging from 505 to $2375 \mathrm{~m}$. A flood regulation ecosystem service can have preventing or mitigating functions. In the first case, the ecosystems (i.e. forests) redirect or absorb parts of the incoming water (from rainfall), reducing in such a way the surface runoff and, consequently, the amount of river discharge. This ecosystem service plays its role before 
flood occurrence and, in some cases, it can even prevent it. However, the flood mitigation function comes into effect when the flood has already taken place. The ecosystems (i.e. floodplains and wetlands) provide retention space for the water surplus to spill, thus reducing the flood's destructive power (Nedkov and Burkhard 2012). In a mountainous watershed with limited or no floodplains, such as Vidima, the prevention function is dominant. Therefore, the assessment should be directed to define the capacity of ecosystems in the watershed to retain part of the rainfall water.

The approach relies on GIS based hydrological modelling performed through the extension ArcGIS AGWA2. It incorporates the KINEROS model, which is suitable for application in relatively small (up to $100 \mathrm{~km}^{2}$ ) watersheds with predominantly surface runoff. The model simulates water balance parameters within the watershed, which are used to quantify the regulation function for the different ecosystems. The outputs of the model used as indicators for flood regulation are infiltration, surface runoff and peak flow. The transformation of the model results to land cover classes has been carried out following the approach proposed by Nedkov and Burkhard 2012. The capacities of the land cover classes were assessed on a relative scale ranging from 0 to 5 (after Burkhard et al. 2009).

\section{Carbon storage mapping in urban ecosystems}

Carbon storage is one of the most common indicators for assessing global climate regulation. It is defined as the amount of carbon stored in the vegetation and soil measured in tC/ha. For calculation and mapping of carbon storage of urban ecosystems in Bulgaria, Nedkov et al. 2017 developed an approach based on an integrated index of spatial structure of the urban ecosystems. It combines data from different ecosystem parameters in the GIS environment to build a spatial proxy model that allows calculation of carbon storage in high resolution at city level (Nedkov et al. 2017). For the town of Karlovo, the study uses the urban ecosystems database developed through TUNESinURB project. The amount of carbon for each polygon of the urban ecosystems database is calculated through an algorithm of six main steps. First, the green area of each polygon is calculated using vegetation cover index (percent) and the area of the polygon (in ha). Next, the green area is differentiated into grass, scrub and tree parts using the data from the land cover part of the integrated index. At the third step, the amount of carbon in grass, shrubs and trees is calculated using reference values from literature sources. At the next step, soil carbon is calculated using data from a digital soil map and reference values from literature sources (Koynov et al. 1998, Zhiyanski et al. 2013, Zhiyanski et al. 2015). The fifth step is calculation of the amount of carbon in $\mathrm{tC}$ per polygon and, at the final step, the amount of carbon per hectare $(\mathrm{tC} / \mathrm{ha})$ is calculated for each polygon of the database. More details of the calculation procedure are provided in Nedkov et al. 2017.

\section{Integration and communication}

The ecosystem assessment combines data and methods from various disciplines and the results could address different aspects of the ecosystem condition or ES delivery (in biophysical, social or economic terms). They have to be integrated in a proper manner in order to address the respective policy needs. In the context of MAES, the integration of 
results needs to combine the knowledge on ecosystem condition and ES to address key questions (Burkhard et al. 2018). The main question in the case studies above is how the assessment can support the integration of ecological functions of the National Park with the economic opportunities that it creates for the local communities (see section Policy context). To address this question, it is of vital importance to have effective communication with the decision-makers and local societies. This means that the results have to be translated into information that is comprehensible for the general public, rather than experts in research.

The integration of ecosystem condition and services is embedded in the methodological framework for mapping and assessment in Bulgaria, as both of them are assessed in the same relative scale. This allows convenient and easy interchange of data and results from different indicators of condition or services. Nedkov et al. 2017 present the use of one urban ecosystem condition indicator (integrated index of spatial structure) in the assessment of different ecosystem services. One of them is the calculation of carbon storage in urban ecosystems which is applied also in this work for the town of Karlovo. The use of a uniform relative assessment scale also allows the convenient preparation of ES maps. For these purposes, the studies utilise the 0 to 5 assessment scale (see section Identification and initial ES mapping) which is applicable for both qualitative and quantitative indicators. This scale can be used for expert based assessment, as well as with quantitative data, such as $C$ t/ha for the carbon storage and $\mathrm{m}^{3} / \mathrm{sec}$ for flood regulation. In the second case, the quantitative data can be arranged into corresponding intervals using statistical methods in order to normalise them to the relative assessment scale. The use of a special colour scheme for all maps also facilitates the communication of the results and better supports the decision-making process.

\section{Results}

\section{Identification and mapping of ecosystems and their services}

There are 20 ecosystem services identified as relevant for the selected case study area (Fig. 5). The results of the expert-based assessment show that the forests have the highest capacity for ES supply. Mixed forests have the highest average score (3.68) followed by broad leaved forests (3.66) and coniferous forests (3.44). Transitional woodland-shrub (2.72), green urban areas (2.48) and natural grassland (247) are the other high-rated land cover types. Dump sites (0.05), bare rocks $(0.41)$ and industrial areas (051) have the lowest capacity.

The results for regulating services are almost the same, while, for provisioning services the overall capacity of forests is similar to the other natural vegetation classes and close to the agricultural classes. The results for cultural services are slightly different, as the discontinuous urban fabric has the highest score. In general, both urban areas and forests exhibit similar (high) scores. All three forest types have very high supply capacity for regulation of pollution, water flow, flood regulation and provision of raw materials. 
Coniferous forests have a slightly lower score for erosion regulation, wild animals' provision and aesthetic value. The main reason here is rooted in the coniferous forests in the area that are planted mostly outside their natural habitat. Pollination, maintenance of habitats and aesthetic value are the services with a higher average score, while cultural heritage is the service with the lowest average score.

\begin{tabular}{|c|c|c|c|c|c|c|c|c|c|c|c|c|c|c|c|c|c|c|c|c|c|c|c|c|}
\hline CLC classess & 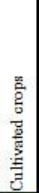 & 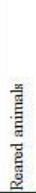 & 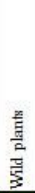 & 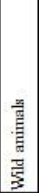 & $\frac{5}{3}$ & 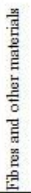 & 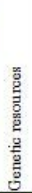 & 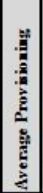 & 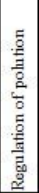 & 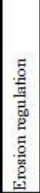 & 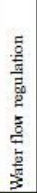 & 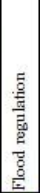 & 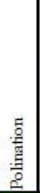 & 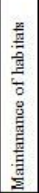 & 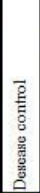 & 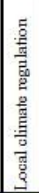 & 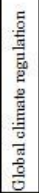 & 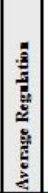 & 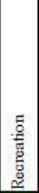 & 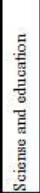 & 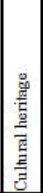 & 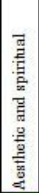 & 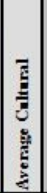 & 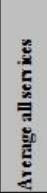 \\
\hline Discontinvous urban fabric & \begin{tabular}{|l|}
3 \\
\end{tabular} & 3 & 2 & 1 & 2 & 2 & 2 & 2,1 & 2 & 2 & 2 & 2 & 3 & \begin{tabular}{|l|}
2 \\
\end{tabular} & 2 & 2 & 1 & 2,1 & 4 & 3 & 4 & 3 & 3,6 & 2,40 \\
\hline Industrial or commercial & 0 & 0 & 0 & 0 & 1 & 1 & 0 & 0,3 & 0 & 1 & 1 & 1 & 1 & 1 & 0 & 0 & 0 & 0,5 & 1 & 1 & 1 & 0 & 0,7 & 0,51 \\
\hline Dump sites & 0 & 0 & 0 & 0 & 0 & 0 & 0 & 0,0 & 0 & 0 & 0 & 0 & 0 & 0 & 0 & 0 & 0 & 0,1 & 0 & 0 & 0 & 0 & 0,0 & 0,05 \\
\hline Green urban areas & 0 & 1 & 2 & 1 & 2 & 2 & 2 & 1,5 & 4 & 3 & 3 & 3 & 3 & 3 & 3 & 4 & 2 & 3,0 & 4 & 2 & 2 & 4 & 3,0 & 2,48 \\
\hline Sport and leisure facilities & 0 & 0 & 1 & 1 & 2 & 1 & 1 & 1,1 & 2 & 2 & 2 & 2 & 2 & 1 & 2 & 2 & 1 & \begin{tabular}{|l|}
1,7 \\
\end{tabular} & 4 & 2 & 1 & 3 & \begin{tabular}{|l|}
2,6 \\
\end{tabular} & 1,64 \\
\hline Non-irrigated arable land & 5 & 2 & 0 & 2 & 2 & 1 & 2 & 1,9 & 2 & 1 & 1 & 1 & 3 & 2 & 2 & 1 & 0 & 1,3 & 0 & 1 & 1 & 1 & 0,9 & 1,43 \\
\hline Vineyards & 4 & 1 & 1 & 1 & 2 & 1 & 2 & 1,6 & 2 & 2 & 2 & 2 & 3 & 2 & 2 & 2 & 0 & 1,7 & 2 & 2 & 1 & 2 & 1,4 & 1,62 \\
\hline Frvit trees and berries & 5 & 2 & 2 & 1 & 2 & 2 & 3 & 2,3 & 3 & 3 & 3 & 3 & 4 & 3 & 2 & 3 & 1 & 2,7 & 1 & 2 & 1 & 2 & 1,3 & 2,28 \\
\hline Pastures & 1 & 4 & 2 & 2 & 2 & 1 & 3 & 2,3 & 2 & 3 & 2 & 2 & 4 & 4 & 3 & 2 & 1 & 2,5 & 2 & 1 & 0 & 2 & 1,4 & 2,20 \\
\hline Complex cultivation pattern & 4 & 3 & 2 & 2 & 2 & 1 & 2 & 2,2 & 2 & 2 & 2 & 2 & 3 & 2 & 2 & 2 & 1 & \begin{tabular}{|l|}
1,9 \\
\end{tabular} & 1 & 1 & 0 & 2 & 0,9 & 1,82 \\
\hline Agro-forestry & 4 & 3 & 3 & 2 & 2 & 2 & 3 & 2,7 & 3 & 2 & 3 & 2 & 3 & 3 & 3 & 2 & 1 & 2,4 & 1 & 1 & 0 & 2 & 1,2 & 2,25 \\
\hline Broad-leaved forest & 0 & 1 & 4 & 5 & 4 & 5 & 4 & 3,2 & 5 & 5 & 5 & 5 & 4 & 4 & 4 & 5 & 3 & 4,2 & 4 & 3 & 1 & 5 & \begin{tabular}{|l|}
3,1 \\
\end{tabular} & 3,66 \\
\hline Coniferous forest & 0 & 1 & 3 & 4 & 4 & 5 & 3 & 2,8 & $\frac{5}{5}$ & 4 & 5 & 5 & 3 & 4 & 3 & 5 & 3 & 4,1 & 4 & 3 & 1 & 4 & 3,0 & 3,44 \\
\hline Mixed forest & 0 & 1 & 4 & 5 & 4 & 5 & 4 & 3,2 & 5 & 5 & 5 & 5 & 4 & 4 & 4 & 5 & 4 & \begin{tabular}{|l|}
4,3 \\
\end{tabular} & 4 & 3 & 1 & 5 & \begin{tabular}{|l|}
3,1 \\
\end{tabular} & 3,68 \\
\hline Natural grasslands & 1 & 4 & 2 & 3 & 2 & 1 & 3 & 2,3 & 2 & 3 & 3 & 2 & 4 & 4 & 4 & 3 & 1 & \begin{tabular}{|l|}
2,7 \\
\end{tabular} & 3 & 2 & 0 & 3 & 2,1 & 2,47 \\
\hline Moors and heathland & 1 & 3 & 2 & 3 & 2 & 1 & 3 & 2,1 & 3 & 3 & 3 & 3 & 4 & 4 & 3 & 3 & 1 & 2,7 & 2 & 2 & 0 & 3 & \begin{tabular}{|l|}
1,7 \\
\end{tabular} & 2,33 \\
\hline Transitional woodland-shrub & 0 & 2 & 4 & 3 & 3 & 3 & 3 & 2,6 & 3 & 3 & 3 & 3 & 4 & 4 & 3 & 3 & 2 & 3,1 & 3 & 2 & 0 & 3 & 2,0 & 2,72 \\
\hline Bare rocks & 0 & 0 & 0 & 1 & 0 & 0 & 1 & 0,2 & 0 & 0 & 0 & 0 & 0 & 1 & 0 & 0 & 0 & 0,1 & 1 & 2 & 0 & 3 & 1,4 & 0,41 \\
\hline Sparsely vegetated areas & 0 & 1 & 1 & 1 & 1 & 0 & 1 & 0,8 & 1 & 1 & 1 & 0 & 1 & 1 & 1 & 1 & 0 & 0,7 & 1 & 1 & 0 & 2 & 0,9 & 0,81 \\
\hline Water bodies & 0 & 1 & 1 & 4 & 5 & 1 & 3 & 2,0 & 3 & 0 & 2 & 2 & 1 & 4 & 2 & 4 & 2 & 2,1 & 4 & 3 & 1 & 4 & 2,8 & 2,21 \\
\hline
\end{tabular}

Figure 5.

Assessment matrix of the capacities of different land cover classes to supply ecosystem services in the Central Balkan case study area.

The results of the expert-based assessment of the land cover classes have been transposed to ecosystems following the scheme, provided by Maes et al. (2013). The results presented in Fig. 6 show that woodland and forest ecosystems have the highest score but very high capacity is assigned only for one service - local climate regulation. This is due to the lower scores of the transitional woodland shrub land cover class which is part of this ecosystem type. Sparsely vegetated ecosystems have the lowest capacity with 0 scores for more than half of the services. Urban ecosystems have low or relevant capacity for all services which means that they provide a variety of services but their capacity is low. The scores for grassland and fresh water ecosystems range from 0 to 5 , which means that they are "specialised" in provision of certain services, but have low capacity in others.

The results from the matrix, presented in Figure 4, have been summarised to prepare a map of the overall ecosystem services supply capacity (Fig. 7A) with separate maps for the provisioning, regulation and cultural service in the Central Balkan area (Fig. 7 B, C and D). Mountain areas generally exhibit higher capacity to provide ecosystem services which is especially valid for regulating services. This is mainly due to their abundant forest vegetation cover. 


\begin{tabular}{|c|c|c|c|c|c|c|c|c|c|c|c|c|c|c|c|c|c|c|c|c|c|c|c|c|}
\hline CLC classess & 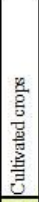 & 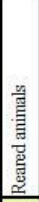 & \begin{tabular}{|l|}
$\frac{2}{2}$ \\
$\frac{2}{2}$ \\
$\frac{2}{2}$ \\
$\frac{3}{3}$
\end{tabular} & 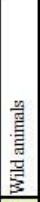 & 总 & 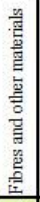 & 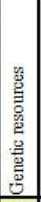 & 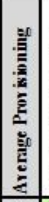 & 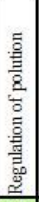 & 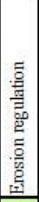 & 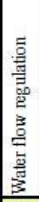 & 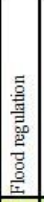 & 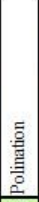 & 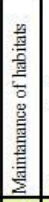 & 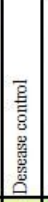 & 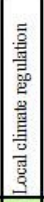 & 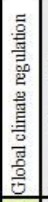 & 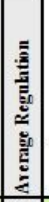 & 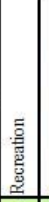 & 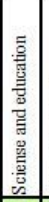 & 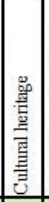 & 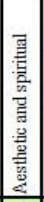 & 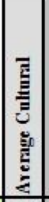 & 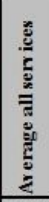 \\
\hline Urban & 1 & 1 & 1 & 1 & \begin{tabular}{|l|}
1 \\
\end{tabular} & \begin{tabular}{|l|}
1 \\
\end{tabular} & 1 & 1,0 & 2 & 2 & 1 & 1 & \begin{tabular}{|l|}
2 \\
\end{tabular} & 1 & 1 & 2 & 1 & 1,5 & 2 & 2 & 2 & 2 & 2,0 & 1,42 \\
\hline Cropland & - & 2 & 1 & 2 & \begin{tabular}{|l|}
2 \\
\end{tabular} & \begin{tabular}{|l|}
1 \\
\end{tabular} & 2 & 2,1 & \begin{tabular}{|l|}
2 \\
\end{tabular} & \begin{tabular}{|l|}
2 \\
\end{tabular} & 2 & 2 & 3 & 2 & 2 & 2 & 1 & 2,0 & 1 & 1 & 0 & 2 & 1,2 & 1,88 \\
\hline Grasst: & 1 & 4 & 2 & 3 & \begin{tabular}{|l|}
2 \\
\end{tabular} & \begin{tabular}{|l|}
1 \\
\end{tabular} & 3 & \begin{tabular}{|l|l|}
2,3 \\
\end{tabular} & \begin{tabular}{|l|}
2 \\
\end{tabular} & 3 & 2 & 2 & 1 & 4 & 3 & 2 & 1 & 2,6 & 2 & 2 & 0 & 3 & 1,8 & 2,33 \\
\hline Woodland a & 0 & 1 & 4 & 4 & 4 & \begin{tabular}{|l|}
4 \\
\end{tabular} & 4 & \begin{tabular}{|l|}
3,0 \\
\end{tabular} & 4 & 4 & 4 & 4 & 4 & 4 & 3 & 5 & 3 & 4,0 & 4 & 3 & 1 & 4 & 2,8 & 3,37 \\
\hline Heathland & 1 & 3 & 2 & 3 & 2 & 1 & 3 & 2,1 & 3 & 3 & 3 & 3 & 4 & 4 & 3 & 3 & 1 & $2,7 \mid$ & 2 & 2 & 0 & 3 & $1,7 \mid$ & 2,33 \\
\hline Sparcely ve & 0 & 0 & 0 & 1 & 1 & 0 & 1 & \begin{tabular}{|l|}
0,5 \\
\end{tabular} & 0 & 0 & 0 & 0 & 1 & 1 & 0 & 0 & 0 & 0,4 & 1 & 1 & 0 & 2 & 1,2 & 0,61 \\
\hline Fresh water & 0 & 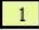 & 1 & 4 & & 1 & 3 & 2,0 & 3 & 0 & 2 & 2 & 1 & 4 & 2 & 4 & 2 & 2,1 & $L^{4}$ & 3 & 1 & 41 & 2,8 & 2,21 \\
\hline
\end{tabular}

Figure 6.

Assessment matrix of the capacities of ecosystems to supply ecosystem services in the Central Balkan case study area.

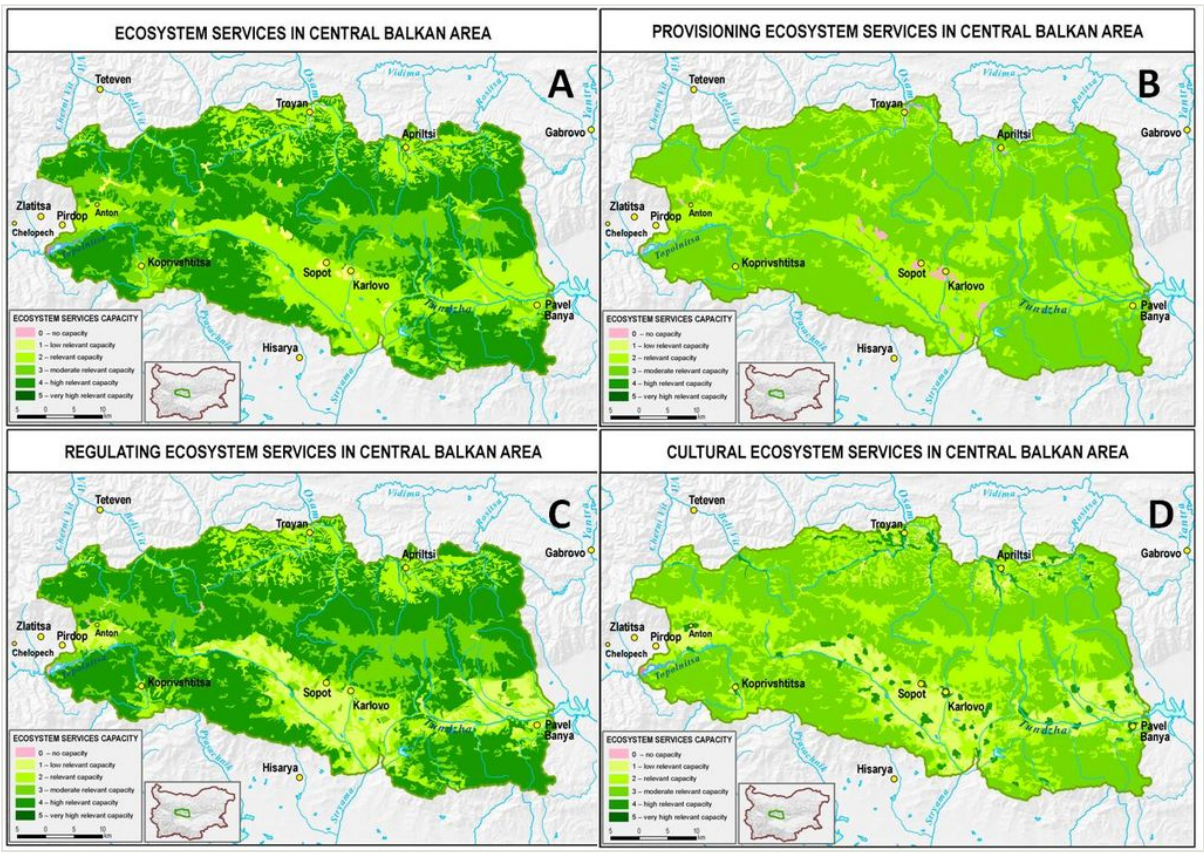

Figure 7.

Maps of ecosystem services in the Central Balkan case study area based on expert evaluation (high-resolution versions are presented as Suppl. materials 2, 3, 4, 5)

\section{Economic valuation of Karlovo Municipality}

The ever-present question of geospatial boundaries within which to conduct any research study is especially pronounced in the case of the boundaries of particular ecosystems and the geographic limits of impact of the services they provide. In view of the main purpose of 
this research - decision-making support and facilitation of sustainable governance administrative territorial boundaries are found most practical (Koulov et al. 2017).

Based on Karlovo Municipality's geography, the economic valuation of its ecosystems and their services (Koulov et al., 2017) involves five ecosystem classes (level 2 in Maes et al. 2013) and 11 ecosystem sub-classes (level 3 in Maes et al. 2013), represented by respective CLC Classes. The initial data analysis amply demonstrates that three basic subclasses - Broad-leaved Forest, Non-irrigated Arable Land and Natural Grassland dominate the Municipality's ecosystems.

Based on the assessment of the local demographic, economic and ecosystems status, 11 classes (CICES 4.3) and 29 class types have been identified and selected as representative ES of the Municipality. The established key provisioning ES include Cultivated Crops, Reared Animals and their Outputs, Wild Plants, Algae and their Outputs and Surface Water for Drinking. The key regulation ES feature Mass Stabilisation and Control of Erosion Rates, Hydrological Cycle and Water Flow Maintenance and Global Climate Regulation by Reduction of Greenhouse Gas Concentrations. Finally, the selected cultural ES comprise Physical Use of Land-/Seascapes in Different Environmental Settings.

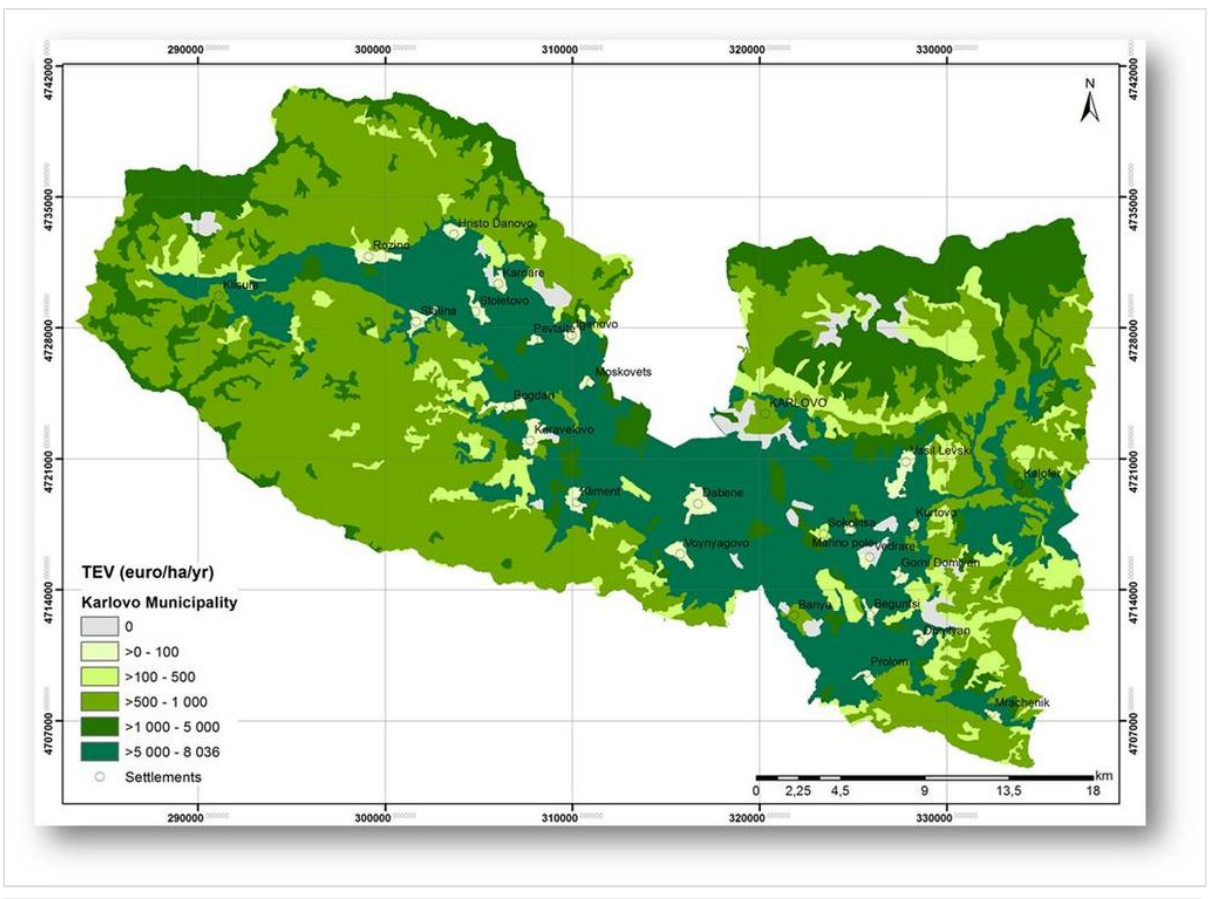

Figure 8.

Total ecosystem services value in Karlovo municipality (after Koulov et al. 2017)

The TEV of the selected, currently utilised ES in the Municipality has been estimated at nearly $€ 115$ million. The most intensively used ecosystems for agricultural purposes at 
Karlovo Valley's bottom are responsible for the majority of the ES production. Three ES Cultivated Crops, Rearing Animals (a.k.a. animal husbandry) and Global Climate Regulation by Reduction of Greenhouse Gas Concentrations - hold the highest shares in the TEV structure. The Broad-leaved and Mixed Forests are most significant subclasses in terms of ES hotspots (Fig. 8).

The critical analysis of the methods applied shows that the disproportion in data availability amongst provisioning, regulation and cultural ES often leads to an artificial increase in the Provisioning ES share in the structure of the TEV. On the other hand, the majority of data about regulation and cultural ES is more circumstantial and much less objective.

\section{Biophysical mapping at watershed and town level}

\section{Flood regulation mapping in Vidima Watershed}

The results of hydrological modelling have been used to estimate the flood regulation capacities of land cover classes, according to the following three indicators: infiltration, peak flow and surface runoff (Table 2). For peak flow and surface runoff, lower water quantities mean higher capacity because more water has been retained by the landscape and less water goes to the surface runoff, respectively to river discharge. For infiltration, the relation is opposite, higher quantity means higher capacity as the water, which is infiltrated into the soil, does not go directly to the river discharge.

Table 2.

Ranges of the model result values for to estimate flood regulation ecosystem service supply capacity.

\begin{tabular}{|l|l|l|l|}
\hline Capacity & Infiltration $(\mathrm{mm})$ & Peak flow $(\mathrm{mm})$ & Surface runoff $(\mathrm{mm})$ \\
\hline 0 & $34.15-36.24$ & $17.41-14.81$ & $13.74-11.55$ \\
\hline 1 & $36.25-38.33$ & $14.80-12.20$ & $11.54-9.35$ \\
\hline 2 & $38.34-40.42$ & $12.19-9.59$ & $9.34-7.16$ \\
\hline 3 & $40.43-42.51$ & $9.58-6.98$ & $7.15-4.96$ \\
\hline 4 & $42.52-44.60$ & $6.97-4.37$ & $4.95-2.76$ \\
\hline 5 & $44.61-46.69$ & $4.36-1.75$ & $2.75-0.55$ \\
\hline
\end{tabular}

The capacity for flood regulation defined on the basis of modelling results has been calculated for the land cover classes in the studied watershed using a GIS-based procedure (Nedkov and Burkhard 2012). The overall relevant capacities of the land cover classes have been defined as average values between the capacities estimated on the basis of the three indicators presented in Table 3. The results show that very high capacity for flood regulation is calculated for coniferous and mixed forests (Table 3). Broad-leaved forests have high capacity while the Urban and the Bare rock classes have no capacity. In general, the land cover classes with higher vegetation cover exhibit higher capacities. This is due to their higher ability to "catch" and retain a larger share of the incoming precipitation 
water. The land cover classes with almost no vegetation cover (i.e. urban, bare rocks) have no relevant capacity.

Table 3.

Flood regulating ecosystem service supply capacities of the different land cover classes in Vidima watershed.

\begin{tabular}{|l|l|}
\hline Land cover classes & Flood regulation capacity \\
\hline 112 Discontinuous urban fabric & 0 \\
\hline 121 Industrial or commercial units & 0 \\
\hline 211 Non-irrigated arable lands & 1 \\
\hline 222 Fruit trees and berries & 3 \\
\hline 231 Pastures & 2 \\
\hline 242 Complex cultivation patterns & 3 \\
\hline 243 Agriculture and natural vegetation & 3 \\
\hline 311 Broad-leaved forests & 4 \\
\hline 312 Coniferous forests & 5 \\
\hline 313 Mixed forests & 5 \\
\hline 321 Natural grasslands & 2 \\
\hline 322 Moors and heathland & 3 \\
\hline 324 Transitional woodland-shrub & 3 \\
\hline 332 Bare rocks & 0 \\
\hline 333 Sparsely vegetated areas & 1 \\
\hline
\end{tabular}

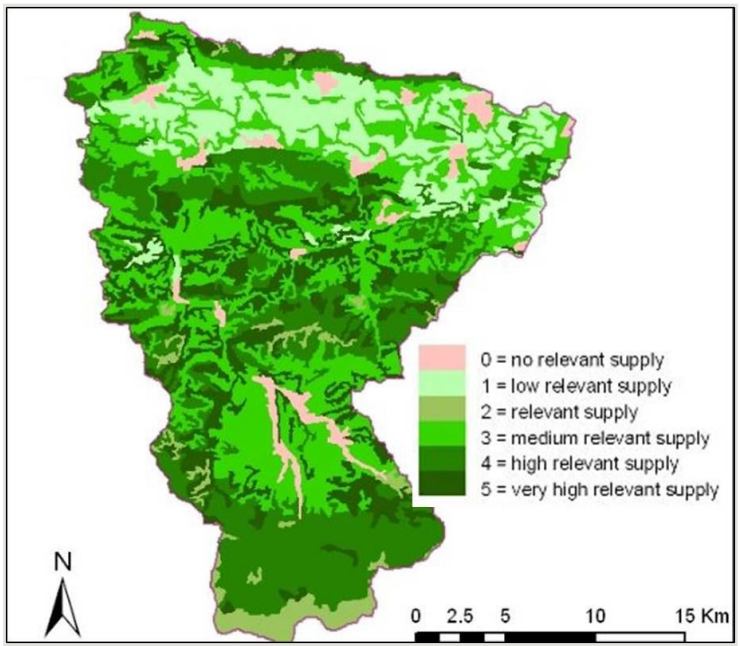

Figure 9.

Flood regulation supply capacity in Vidima watershed (after Boyanova et al. 2014). 
The map of flood regulation supply capacities (Fig. 9) shows that the watershed of Vidima River has relatively high capacities for flood regulation. Areas of high and very high relevant capacities cover about $38 \%$ of the study area. They are located predominantly in the areas with higher elevation in the southern and central parts of the watershed. This is mainly due to

the relatively high share of forest land cover types in this area. The areas with low and no relevant capacities comprise about $15 \%$ of the watershed. They are located mainly in the northern part of the watershed where the river valley is wide and relatively flat which allows for more and larger urban and agricultural areas.

\section{Carbon storage mapping in the Town of Karlovo}

The urban ecosystems in the town of Karlovo have been identified and mapped according to the typology of the urban ecosystems developed by Zhiyanski et al. 2017. Seven, out of a total of ten, urban ecosystem subtypes were identified in the study area: J1 - Residential and public areas of cities and towns, J3 - Residential and public low density areas; J5 Urban green areas (including sport and leisure facilities), J6 - Industrial cities (including commercial sites), J7 -Transport network and other constructed hard surfaced sites), J9 Waste deposits, J10 - Highly artificial man-made water basins and associated structures. The last subtype is represented by only one small patch which is not representative and, therefore, has been excluded from the assessment calculations. The carbon storage capacity and its spatial distribution are almost exclusively determined by the land cover of the respective ecosystem and its area. The carbon storage (in $\mathrm{C} t / \mathrm{ha}$ ) has been calculated for each polygon of the urban ecosystems dataset using the approach based on an integrated index of spatial structure (Nedkov et al. 2017). For the town of Karlovo, the figures vary from 0 to $83.64 \mathrm{C}$ t/ha. The polygons with 0 values have been defined as having no capacity for carbon storage. The other values have been distributed in five intervals from 1 (low capacity) to 5 (very high capacity) using the statistical method of the Natural Breaks (Table 4).

Table 4.

Carbon storage supply capacities according to the amount of carbon per polygon. The capacity classes correspond to the classes in Fig. 8.

\begin{tabular}{|l|l|l|l|l|l|l|}
\hline Capacity & 0 & 1 & 2 & 3 & 4 & 5 \\
\hline C t/ha & 0 & $0.1-33.3$ & $33.4-39.3$ & $39.4-54.5$ & $54.6-66.1$ & $66.1-83.64$ \\
\hline
\end{tabular}

The results from Table 5 have been used to produce a map of carbon storage capacity in the town of Karlovo (Fig. 10). Very high capacity is determined for the urban parks with predominant tree vegetation, such as the "Apostolova gora" Park located in the northwestern part of the town. The other parks in the central area with more grassland and the suburban areas with scattered buildings have high carbon storage capacity. The residential areas, located around the town centre, have low capacity. They are characterised by 
relatively compact mid-rise buildings and low vegetation cover (20-30\%). The other residential areas, characterised by open low-rise buildings and moderate vegetation cover $(40-60 \%)$ have relevant capacity (class 2$)$. No capacity is defined for some of the transport network areas.

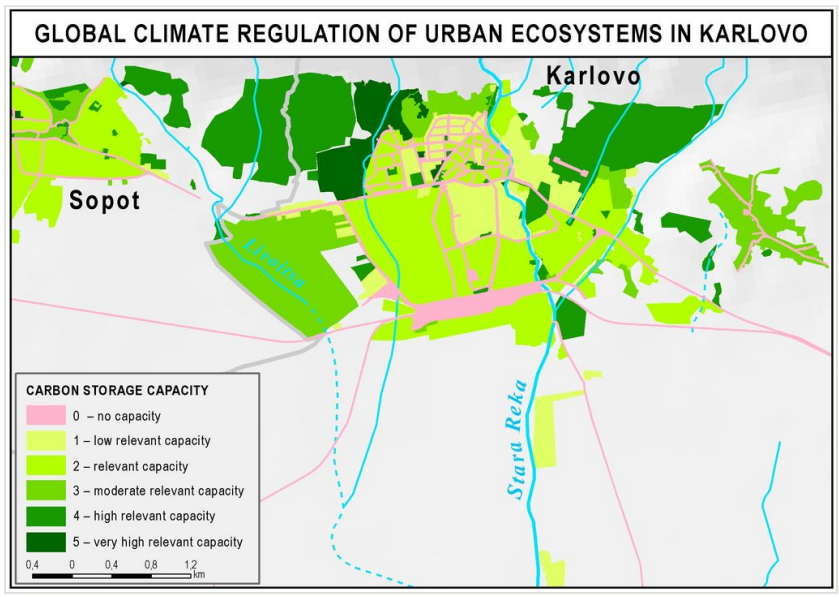

Figure 10.

Map of carbon storage capacity in Karlovo.

The results of the calculation per polygons have been used to summarise the carbon storage in the different ecosystem subtypes, in the elements of the vegetation and soils, as well as in the town as a whole (Table 5). The overall amount of carbon in Karlovo is estimated at $49622 \mathrm{t}$. More than $70 \%$ of this amount is in the soil and the rest is in the tree vegetation. The amount of carbon in grass and shrubs is very low. The highest overall amount of carbon is in the residential and public low density areas (J3) and is due to their large area. The highest average amount of $\mathrm{C} t / \mathrm{h}$ is in the green area (65.2) while the lowest is in the transport networks (10.7).

Table 5.

Carbon storage in the urban ecosystem in Karlovo in tC.

\begin{tabular}{|l|l|l|l|l|l|l|l|}
\hline & C soil & C trees & C schrub & C grass & C veg & C Total & C t/ha \\
\hline J1 & 5980 & 2823 & 0 & 102 & 2925 & 8905 & 39.1 \\
\hline J3 & 18392 & 5676 & 8 & 314 & 5999 & 24391 & 51.8 \\
\hline J5 & 6565 & 1383 & 5 & 117 & 1505 & 8070 & 65.2 \\
\hline J6 & 4825 & 1627 & 0 & 94 & 1721 & 6546 & 39.2 \\
\hline J7 & 575 & 817 & 0 & 10 & 827 & 1403 & 10.7 \\
\hline J9 & 297 & 0 & 0 & 10 & 10 & 307 & 18.2 \\
\hline sum & 36636 & 12327 & 13 & 646 & 12986 & 49622 & \\
\hline
\end{tabular}




\section{Discussion and conclusions}

\section{Discussion}

This paper follows the general structure of the framework for integrated mapping and assessment of ecosystem services provided by Burkhard et al. 2018 in the Central Balkan case study area. It organises data and methods from various research fields and with different quality and levels of complexity in a logical chain, which can be effectively applied to support policy-making. The examples of ES mapping at different scales provide a good basis for the comparison, analysis and interpretation of the results with respect to different policy questions which arise in general relation and mutual interdependency.

The spreadsheet application enables the identification of the concrete bundle of ecosystem services in the case study area and the execution of the initial ES assessment. The results can be conveniently presented in the form of maps for either individual or bundles of ecosystem services. The maps of the Central Balkan area, presented above, show a very high supply capacity for regulating services, including flooding and global climate regulation. These results are mainly based on expert judgment and should be considered just as a starting point for further more precise assessment. The method itself is very useful for the identification of ES delivered by ecosystems at step $4 \mathrm{~b}$ from the Burkhard et al. (2018) framework.

The biophysical methods applied in this study ensure quantification of ES indicators for two important services: flood regulation and global climate regulation. Mountain watersheds in the case study area are characteristic for their high supply capacity for flood regulation, due to the high degree of forestation. At the same time, the area is flood prone, due to the high frequency of heavy rains on the north steep mountain slopes of the Balkan Mountain Range. Therefore, further work in this field should be directed to mapping and assessment of flood regulation demand in order to support the policy for natural hazard prevention. This important issue is related to many different policy aspects, such as planning adaptation to climate change extremes, investment efficiency etc. To address them adequately, it is best to focus on tier 3 level and use scenario-based mapping of flood regulation ES. In this way, flood risk managers will be able to choose optimal management decisions and to integrate the results of the assessment in the particular policy context.

The global climate regulation approach relies on estimations of carbon storage in the vegetation and soils. The uncertainty in the assessments of soil organic carbon storage is due to errors in soil density and rock fraction estimates, lack of data on organic carbon variability and missing or poorly quantified data for below-ground biomass and environmental control parameters. Information about above-ground biomass in different vegetation cover types also needs more detail. Carbon storage in soil and vegetation is strongly influenced by the size of the area covered by each urban ecosystem subtype and the presence or absence of some ecosystem subtypes in the given territory. That is the reason whythe assessment has to be carried out in accordance with an analysis of the spatial infrastructure of the respective territory (Nedkov et al. 2017). The information for 
biomass amount in the variety of vegetation cover types and in different types of urban greening in Bulgarian settlements is not complete and further work on this problem is recommended. The role of climate regulating ES is expected to increase in the future, due to the climate change.

The data collection and mapping approaches used in the Karlovo Case Study involve significant generalisations. These show weaknesses in the case of concrete ecosystems or business localisations and are, therefore, more suitable for strategic analyses. Another, often overlooked "mapping" discrepancy, is related to the large share of tourism and recreation services consumed in the natural ecosystems, while the largest part of the actual reporting and accounting happens and is mapped in the urban areas' services (Koulov et al. 2017). Such challenges can be avoided through detailed fieldwork, targeted territorial evidence gathering and in situ monitoring on a case-by-case basis.

Practical application of ES knowledge enables the territorial integration of interests, activities, policies and overall governance. This, in turn, creates a basis for active management of ecosystems as service sources, while maintaining a sustained motivation for the local community and other stakeholders to cooperate in the process. The expected long-term outcome is to achieve simultaneous results in the environmental, social, cultural, political and economic aspects of sustainable development in the respective area.

\section{Conclusions}

In the last 10 years, ecosystem services' studies in Bulgaria provide a consistent and fast developing basis for further development of the concept and its application in policy- and decision-making. Promising results have been achieved particularly in biophysical assessment of flood regulation, erosion regulation and carbon storage, which were mapped in several case studies throughout the country. The spreadsheet, spatial proxy and process-based methods have been used in the process. Promising results have also been in the application of economic methods, such as contingent valuation, market price and value transfer, which have been applied with considerable success for bundles of ecosystem services in several case studies. The methodological framework for mapping and assessment of ecosystems and their services at national level ensures widespread implementation of the MAES process in the country. The results of its application for the main ecosystem types in the country provide the initial database for mapping and assessment of a constantly widening range of ecosystem services.

The Central Balkan case studies provide relevant examples for implementation of integrated mapping and assessment of ecosystem services at local level. Following the Burkhard et al. (2018) framework, they have identified the main public policy themes and topics in the area, amongst which are the integration of nature protection areas management and the planning regions (NUTS2), district (oblast) and municipality (obshtina) socio-economic development plans. One of the main problems for the identification and assessment and ecosystems is the lack of appropriate data for delineation of all ecosystem types and quantification of all ecosystem services' indicators. The application of multi-tiered approach gives the opportunity to integrate a wider range of 
spatial and non-spatial databases with different quality and utilisation of analyses, as well as various level of complexity. The spreadsheet method, implemented at tier 1 , allows the identification of the relevant ecosystems and their services, while the economic assessment methods at tier 2 allowed valuation of five ecosystem types and 11 ecosystem services in Karlovo Municipality with a total economic value of nearly $€ 115$ million. The ecosystem services assessment at tier 3 necessitates detailed data and application of more complex modelling methods. At this level, ES assessment has focused mainly on quantification and mapping of flood regulation and carbon storage. The hereby generated maps at all levels use a uniform assessment scale which ensures a clear communication of the end results to the respective decision-makers.

\section{Acknowledgements}

This study is supported by ESMERALDA (Enhancing ecosystem sERvices mApping for poLicy and Decision mAking) project funded by the European Union's Horizon 2020 research and innovation programme under grant agreement No 642007 (http:// www.esmeralda-project.eu/). The study is also supported by: the "National, European, and Civilizational Dimensions of the Culture - Language - Media Dialogue" Programme of the "Alma Mater" University Complex for the Humanities at Sofia University "Saint Kliment Ohridski", funded by the Bulgarian Ministry of Education, Youth and Science Scientific Research Fund; the project "Toward better understanding of ecosystem services in urban environments through mapping and assessment (TUNESinURB)", funded by the FM of EEA 2009-2014 (www.tunesinurb.org); Project PDP02 - Methodological Support for Ecosystem Services Mapping and Biophysical Valuation (MetEcoSMap), funded by the FM of EEA 2009-2014 (www.metecosmap-sofia.org).

\section{References}

- $\quad$ Assenov A, Borisova B (2016) Value of Ecosystems (Landscape) Services in the Area of the Towns of Apriltsi, Kalofer and Smolyan. Annuals, Sofia University St. Kliment Ohridski 2 (107): 141-163. [In Bulgarian].

- Assenov A, Padeshenko H, Koulov B, E.Ivanova E, Borisova B (2016) Research of the Biotope Diversity for the Purposes of Economic Valuation of Ecosystem Services in Chepelare Municipality (The Rhodopes Region of Bulgaria). In. European Journal of Sustainable Development, Special Issue - 5 (4): 409-420.

- Avetisyan D, Borisova B, Nedkov R (2016) Determination of the Landscapes Regulation Capacity and Their Role in the Prevention of Catastrophic Events: A Case Study from the. In: Koulov, B. and G. Zhelezov (eds.) Sustainable Mountain Regions: Challenges and Perspectives in Southeastern Europe. Lom River Upper, Valley, Bulgaria. URL: http://www.springer.com/gp/book/9783319279039 [ISBN 978-3-319-27903-9.]

- $\quad$ BBF (2016) Bulgarian Biodiversity Foundation "For the Balkans and the Humans" Project won an European Commission. "NATURA 2000" award URL: http:// bbf.biodiversity.bg/bg/PROEKTYT-ZA-BALKANA-I-HORATA-SPEChELI-NAGRADATANATURA-2000-NA-EVROPEYSKATA-KOMISIYa.p1633 (accessed on 25.01.2018) 
- Borisova B (2013) Landscape ecology and landscape planning. Prof. Marin Drinov Academic publishing house,, Sofia, 284 pp. [In Bulgaria]. [ISBN ISBN

978-954-332-670-2]

- Borisova B, Assenov A, Dimitrov P (2015) The Natural Capital of Selected Mountain Areas in Bulgaria. Springer Geography. https://doi.org/10.1007/978-3-319-13527-4_6

- Boyanova K, Nedkov S, Burkhard B (2014) Quantification and Mapping of Flood Regulating Ecosystem Services in Different Watersheds - Case Studies in Bulgaria and Arizona, USA. Lecture Notes in Geoinformation and Cartography. https:// doi.org/10.1007/978-3-319-08180-9 18

- Boyanova K (2015) Spatial analysis and assessment of ecosystem services in mountain watersheds using geospatial technologies. PhD Thesis, 175 pp. [In Bulgarian].

- Boyanova K, Nedkov S, Burkhard B (2016) Applications of GIS-Based Hydrological Models in Mountain Areas in Bulgaria for Ecosystem Services Assessment: Issues and Advantages. Sustainable Mountain Regions: Challenges and Perspectives in Southeastern Europe. https://doi.org/10.1007/978-3-319-27905-3 3

- Bratanova-Doncheva S, Fikova R, Katrandziev K, Chipev N, Dimitrova V (2014) RESILIENCE OF ECOSYSTEM SERVICES - APPLYING ECOSYSTEM FUNCTION AND INTEGRITY CONCEPTS TO NATURAL SWEET CHESTNUT FORESTS IN BELASITZA MOUNTAIN (SW BULGARIA). Acta Horticulturae 1043: 183-190. https:// doi.org/10.17660/actahortic.2014.1043.24

- $\quad$ Bratanova-Doncheva S, Chipev N, Gocheva K, Vergiev S, Fikova R (2017) Methodological framework for assessment and mapping of ecosystem services in Bulgaria - conceptual basis and principles of application. Clorind. Clorind. [ISBN ISBN 978-619-7379-21-1].

- $\quad$ Burkhard B, Kroll F, Müller F, Windhors W (2009) Landscapes capacities to provide ecosystem services - a concept for land-cover based assessments. Landscape Online 15: 1-22.

- Burkhard B, Petrosillo I, Costanza R (2010) Ecosystem services - Bridging ecology, economy and social sciences. Ecological Complexity 7 (3): 257-259. https:// doi.org/10.1016/j.ecocom.2010.07.001

- $\quad$ Burkhard B, Kroll F, Nedkov S, Müller F (2012) Mapping ecosystem service supply, demand and budgets. Ecological Indicators 21: 17-29. https://doi.org/10.1016/ j.ecolind.2011.06.019

- $\quad$ Burkhard B, Kandziora M, Hou Y, Müller F (2014) Ecosystem Service Potentials, Flows and Demands - Concepts for Spatial Localisation, Indication and Quantification. Landscape Online 1-32. https://doi.org/10.3097/lo.201434

- $\quad$ Burkhard B (2018) Mapping and assessing ecosystems services in the EU - The ESMERALDA coordination and support action approach of integration. One Ecosystem (in preparation).

- $\quad$ Burkhard B, Santos-Martin F, Nedkov S, Maes J (2018) An operational framework for integrated Mapping and Assessment of Ecosystems and their Services (MAES). One Ecosystem 3: e22831. https://doi.org/10.3897/oneeco.3.e22831

- Chipev N, Bratanova-Doncheva S, Kr. Gocheva MZ, Mondeshka M, Yordanov Y, Apostolova I, Sopotlieva D, Velev N, El. Rafailova YU, Karamfilov V, Fikova R, Vergiev S (2017) GUIDE FOR MONITORING OF TRENDS IN ECOSYSTEM CONDITION AND ECOSYSTEM SERVICES. Clorind. [ISBN 978-619-7379-25-9]. 
- $\quad$ Dimitrova L, Petrova D, Belev T, Todorov T, Grigorova-Ivanova J, Shuleva N (2015) Valuation of Ecosystem Services provided by the Forest the Central Balkan National Park. Central Balkan National Park. [In Bulgarian]. URL: http://visitcentralbalkan.net/ assets/userfiles/\%D0\%91\%D0\%B0\%D0\%BB\%D0\%BA\%D0\%B0\%D0\%BD\%D1\%8A\% D1\%82/NPCB_EcosystemServicess.pdf

- Dimitrov S, Georgiev G, Georgieva M, Gluschkova M, Chepisheva V, Mirchev P, Zhiyanski M (2018) Integrated assessment of urban green infrastructure condition in Karlovo urban area by in-situ observations and remote sensing. One Ecosystem 3: e21610. https://doi.org/10.3897/oneeco.3.e21610

- $\quad$ ESMERALDA (2015) Description of Action (DoA). Pensoft, Sofia, 178 pp.

- $\quad$ Geneletti D, Adem Esmail B, Cortinovis C (2018) Identifying representative case studies for ecosystem services mapping and assessment across Europe. One Ecosystem[In preparation].

- $\quad$ Grêt-Regamey A, Walz A, Bebi P (2008) Valuing Ecosystem Services for Sustainable Landscape Planning in Alpine Regions. Mountain Research and Development 28 (2): 156-165. https://doi.org/10.1659/mrd.0951

- Grêt-Regamey A, Weibel B, Kienast F, Rabe S, Zulian G (2015) A tiered approach for mapping ecosystem services. Ecosystem Services 13: 16-27. https://doi.org/10.1016/ j.ecoser.2014.10.008

- $\quad$ Guerry A, Polasky S, Lubchenco J, Chaplin-Kramer R, Daily G, Griffin R, Ruckelshaus M, Bateman I, Duraiappah A, Elmqvist T, Feldman M, Folke C, Hoekstra J, Kareiva P, Keeler B, Li S, McKenzie E, Ouyang Z, Reyers B, Ricketts T, Rockström J, Tallis H, Vira B (2015) Natural capital and ecosystem services informing decisions: From promise to practice. Proceedings of the National Academy of Sciences 112 (24): 7348-7355. https://doi.org/10.1073/pnas.1503751112

- Haines-Young R, Potchin M (2013) CICES V4.3 - Report prepared following consultation on CICES Version 4. Undefined EEA Framework Contract No EEA/IEA/09/003. URL: https://unstats.un.org/unsd/envaccounting/seeaRev/GCComments/CICES_Report.pdf

- Ivanova E, Koulov B, Borisova B, Assenov A, Vassilev K (2016) GIS-based Valuation of Ecosystem Services in Mountain Regions: A Case Study of the Chepelare Municipality in Bulgaria. European Journal of Sustainable Development, Special Issue - 5 (4): 335-346. URL: http://www.ecsdev.org/index.php/publications/ejsd

- Koulov B, Ivanova E, Borisova B, Assenov A, Ravnachka A (2017) GIS-based Valuation of Ecosystem Services in Mountain Regions: A Case Study of the Karlovo Municipality in Bulgaria. One Ecosystem 2: e14062. https://doi.org/10.3897/oneeco.2.e14062

- Koulov B, Borisova B (2018) Ecosystem Services: Concept, Opportunities and Limitations for its Implementation in Bulgaria Scientific Works of USB - Plovdiv. Series B. Natural Sciences and Humanities (in bulgarian) ISSN. Scientific Works of USB Plovdiv. Series B. Natural Sciences and Humanities. [In Bulgarian]. [ISBN ISSN 1311-9192 (in press)].

- Koynov V, Kabakchiev K, Boneva K (1998) Atlas of soils in Bulgaria. Zemizdat, Sofia, $321 \mathrm{pp}$. [In Bulgarian]. [ISBN 954-05-0116-4]

- LAP (2016) Lima Action Plan for UNESCO's Man and the Biosphere (MAB) Programme and its World Network of Biosphere Reserves. UNESCO URL: http://www.unesco.org/ fileadmin/MULTIMEDIA/HQ/SC/pdf/Lima_Action_Plan_en_final.pdf

- Maes J, Teller A, Erhard M, Liquete C, Braat L, Berry P, Egoh B, Puydarrieux P, Fiorina C, Santos F, Paracchini M, Keune H, Hauck J, Fiala I, Verburg P, Conde S, Schagner 
JP, San Miguel J,OO, Estreguil. C, Barredo J, Pereira H, Stott A, Laporte V, Meiner A, Olah B (2013) Mapping and Assessment of Ecosystems and their Services. An analytical framework for ecosystem assessments under. Publications office of the European Union, Luxemburg (57 pp). URL: http://ec.europa.eu/environment/nature/ knowledge/ecosystem_assessment/pdf/MAESWorkingPaper2013.pdf

- Maes J, Zulian G, Thijssen G (2017) Enhancing Resilience Of Urban Ecosystems through Green Infrastructure. Publications Office of the European. Union, Luxemburg URL: http://publications.jrc.ec.europa.eu/repository/bitstream/JRC106443/ enrouteinceptionreportfinal.pdf

- MAF (2014) Ministry of Agriculture and Food, Republic of Bulgaria: Agrostatistical Reference Book. Ministry of agriculture and Food URL: http://www.mzh.government.bg/ MZH/en/ShortLinks/SelskaPolitika/Agrostatistics.aspx

- $\quad$ Markov B, Nedkov S (2016) Mapping of erosion regulation ecosystem services Proceedings, 6th International Conference on Cartography and GIS. In: Bandrova T, Konechni M (Eds) Proceedings, 6th International Conference on Cartography and GIS, 13-17 June 2016. Albena, Bulgaria

- $\quad$ Nedkov S (2011) Landscape Structure and Ecosystem Services of Etropole Municipality. In: Zhelezov G (Ed.) Sustainable Development in Mountain Regions, Southeastern Europe. South Eastern Europe, Springer https://

doi.org/10.1007/978-94-007-0131-1 8

- Nedkov S, Burkhard B (2012) Flood regulating ecosystem services-Mapping supply and demand, in the Etropole municipality, Bulgaria. Ecological Indicators 21: 67-79. https://doi.org/10.1016/j.ecolind.2011.06.022

- Nedkov S, Gikov A, Nikolova M, Dimitrov P, Gachev E (2014) Mapping of ecosystem services in mountain areas: a case study of Seven Rila Lakes 5th International conference on Cartography and GIS. In: Bandrova T, Konechny M (Eds) 5th International conference on Cartography and GIS. Riviera, Bulgaria, 488-497 pp.

- $\quad$ Nedkov S, Zhiyanski M, Nikolova M, Gikov A, Nikolov P, Todorov L (2016) Mapping of carbon storage in urban ecosystems: a Case study of Pleven District, Bulgaria. Proceedings of the scientific conference "Geographical aspects of land use and planning under climate change". URL: http://geography.bg/images/dokladi/33.pdf [ISBN ISBN: 978-619-90446-1-2].

- Nedkov S, Zhiyanski M, Dimitrov S, Borisova B, Popov A, Ihtimanski I, Yaneva R, Nikolov P, Bratanova-Doncheva S (2017) Mapping and assessment of urban ecosystem condition and services using integrated index of spatial structure. One Ecosystem 2: e14499. https://doi.org/10.3897/oneeco.2.e14499

- $\quad$ NRC (2014) National Reference Centre. Ministry of Environment and Water URL: http:// www.nsi.bg/en/content/4247/prices-agricultural-production-data-series

- $\quad$ NSI (2015a) National Statistical Institute, Republic of Bulgaria: Regional statistics data series. National Statistial Institute URL: http://www.nsi.bg/en/content/11252/regionalstatistics-and-indicators-monitoring

- NSI (2015b) National Statistical Institute, Republic of Bulgaria: Prices of agricultural production data series. Nationla Statistical Institute URL: http://www.nsi.bg/en/ content/4247/prices-agricultural-production-data-series

- NSI (2016) National Statistical Institute, Republic of Bulgaria. Demography. National Statistical Institute. 
- $\quad$ Pehlivanov L, Fikova R, Ivanova N, Kalchev R, Kazakov S, Pavlova M, BratanovaDoncheva S (2014) Analysis of Ecosystem Services of Wetlands along the Bulgarian Section of the Danube River. Acta Zoologica Bulgarica.

- $\quad$ Primmer E, Furman E (2012) Operationalising ecosystem service approaches for governance: Do measuring, mapping and valuing integrate sector-specific knowledge systems? Ecosystem Services 1 (1): 85-92. https://doi.org/10.1016/ j.ecoser.2012.07.008

- Rashev B (2003) Alternative Economic Valuation of Pirin National Park, Bulgaria. [Master thesis]. Brandenburg University of Technology, Cottbus, Germany.

- Rosenthal A, Verutes G, McKenzie E, Arkema K, Bhagabati N, Bremer L, Olwero N, Vogl A (2014) Process matters: a framework for conducting decision-relevant assessments of ecosystem services. International Journal of Biodiversity Science, Ecosystem Services \& Management 11 (3): 190-204. https:// doi.org/10.1080/21513732.2014.966149

- $\quad$ Schröter M, Albert C, Marques A, Tobon W, Lavorel S, Maes J, Brown C, Klotz S, Bonn A (2016) National Ecosystem Assessments in Europe: A Review. BioScience 66 (10): 813-828. https://doi.org/10.1093/biosci/biw101

- $\quad$ Sieber I, Bicking S, Adem Esmail B, Arnell A, Brown C, Santos F, Nedkov S, Stoev P, Geneletti D, Maes J, Kopperoinen L, Potschin-Young MaB (2017) ESMERALDA Midterm project Meeting and Workshop VI on Flexible methods for mapping and assessing ecosystem services. ESMERALDA Project, Grant Agreement 642007.

- Tomova K, Borisova B (2018) Biosphere Reserves under the UNESCO's "Man and Biosphere" Programme as a Tool for Regional Development and Understanding the Complete Potential of Ecosystem Services (Using the Example of Central Balkan National Park). Annuals, Sofia University St.Kliment Ohridski 2: 120-143. [In Bulgarian].

- UK, NEA (2011) The UK National Ecosystem Assessment: Synthesis of the Key Findings. UNEP-WCMC, Cambridge.

- $\quad$ UNESCO (1996) Biosphere reserves: The Seville Strategy and the Statutory Framework of the World Network. UNESCO, Paris.

- Zevurdakis M, Rashev B, Germer C (2007) Review of the ecosystem services and the values they provide. Rhodope project. UNDP

- Zhiyanski M, Hursthouse A, Doncheva S (2015) Role of different components of urban and peri-urban forests to store carbon - a case-study of the Sandanski region, Bulgaria. Journal of Chemical, Biological and Physical Sciences. JCBPS, Section D 2015 (5): 3114-3128.

- $\quad$ Zhiyanski M, Gikov A, Nedkov S, Dimitrov P, Naydenova L (2016) Mapping Carbon Storage Using Land Cover/Land Use Data in the Area of Beklemeto, Central Balkan. Sustainable Mountain Regions: Challenges and Perspectives in Southeastern Europe. https://doi.org/10.1007/978-3-319-27905-3 4

- Zhiyanski M, Doncheva S, Nedkov S, Mondeshka M, Yarlovska N, Vasilev V, Borisova B, Chipev N, Gocheva K (2017) Methodology for assessment and Mapping of Urban ecosystems their state, and the services that they provide in Bulgaria. Clorind, $58 \mathrm{pp}$.

- Zhiyanski M, Doichinova V, Petrov K (2013) The social aspects and role of green infrastructure in mitigating climatic changes at regional level. Proceedings of 3rd International Conference "Ecology of urban areas 2013". Zrenjanin 


\section{Supplementary materials}

Suppl. material 1: Ecosystem activities in Bulgaria doi

Authors: Stoyan Nedkov, Bilyana Borisova, Miglena Zhiyanski

Data type: table

Brief description: The table presents review of main ES activities in Bulgaria

Filename: Ecosystem services activities in Bulgaria.pdf - Download file (143.09 kb)

Suppl. material 2: Ecosystem services in Central Balkan area doi

Authors: Julia Kroumova

Data type: Map

Filename: 1_ESS_CB_A5.jpg - Download file (2.52 MB)

Suppl. material 3: Provisioning ecosystem services in Central Balkan area doi

Authors: Julia Kroumova

Data type: map

Filename: 2_PROVISIONAL_ESS_CB_A5.jpg - Download file (2.18 MB)

Suppl. material 4: Regulating ecosystem services in Cenral Balkan area doi

Authors: Julia Kroumova

Data type: map

Filename: 3_REGULATING_ESS_CB_A5.jpg - Download file (2.60 MB)

Suppl. material 5: Cultural ecosystem services in Central Balkan area doi

Authors: Julia Kroumova

Data type: map

Filename: 4_CULTURAL_ESS_CB_A5.jpg - Download file (2.48 MB) 